\title{
Factores psicosociales y cáncer: una revisión crítica
}

\author{
M. ${ }^{a}$ Soledad Blanco Ruiz \\ Verania A. Navia
}

Centro de Terapia y Modificación de Conducta

\section{INTRODUCCION}

Hay una observación básica y muy simple que sirve de fundamento a la investigación psicosomática: ¿por qué cuando distintos individuos son sometidos a influencias ambientales patógenas similares, sólo algunos de ellos desarrollan la enfermedad? Mientras que el objetivo del científico biomédico ha sido normalmente la eliminación de esa variabilidad mediante todos los métodos disponibles, la investigación psicosomática se ha fundamentado precisamente en ella. Tal enfoque reduccionista vigente en la investigación biomédica, con resultados tan satisfactorios durante el siglo pasado en el estudio de la influencia microbiana de algunas enfermedades, ha impedido la verdadera comprensión de los distintos factores que contribuyen al desarrollo de una enfermedad en un individuo dado. En muy pocas ocasiones podríamos afirmar que el hecho de enfermar se debe a un único agente etiológico, y el desarrollo de modelos multifactoriales parece el camino más fructífero si se quieren explicar realmente los procesos relacionados con la enfermedad (e.g.,
Plaut y Friedman, 1981). En este contexto «... el enfoque psicosomático implica el estudio de todas las influencias que contribuyen al mantenimiento y bloqueo de la homeostasis, tal y como se da en el individuo en el curso de su adaptación al mundo real" (Ader, 1980).

La medicina psicosomática, en su versión clásica (e.g., Alexander y Flagg, 1965), ha sido una alternativa aparente a este enfoque reduccionista (Engel, 1977). ¿Y por qué aparente? La razón fundamental es que ha mantenido la orientación dualista del modelo biomédico, reflejada en la idea de que la relación mente-cuerpo se manifiesta en algunas enfermedades '. Esta noción, según la cual habría «enfermedades psicosomáticas", está totalmente en entredicho a la luz del cuerpo considerable de datos de los que se dispone y que la contradicen, parte de los cuales constituyen el objeto de este artículo. A nuestro entender, no existen enfermedades psicosomáticas. Lo que planteamos que existe es una etiologia psicosomática, en el sentido siguiente: los factores psicológicos, siempre presentes a través del Sistema Nervioso Central y sus consiguientes vías de influencia (sobre sistema nervioso au- 


\section{Estudios}

tónomo, endocrino, inmunológico, etc.; véase más adelante), intervienen en la etiología alterando la susceptibilidad del individuo a la enfermedad, no "provocándola». Así pues, el interés del investigador psicosomático está en averiguar qué proporción de la varianza total explican los factores psicológicos frente a los ambientales y estrictamente biológicos. En términos de teoría bayesiana de la probabilidad podríamos decir que la probabilidad de enfermar se ve alterada por las condiciones psicológicas del individuo.

Esta otra concepción, la de eetiología psicosomática" (o modificación de la vulnerabilidad a enfermar atribuible a factores psicológicos), como alternativa a la de "enfermedad psicosomática», es la que, en parte, ha servido como base a la medicina conductual. Decimos «en parte" porque el desarrollo de la medicina conductual ha sido fruto de la confluencia de diversos factores (vid. discusión de Schwartz y Weiss, 1977). No obstante la polémica suscitada tiempo atrás por el término y por la propia área, una definición de «medicina conductual" relativamente consensuada y general podría ser la de la aplicación de los conocimientos proporcionados por las ciencias del comportamiento y las biomédicas, conjuntamente, al conocimiento, prevención, diagnóstico, tratamiento y rehabilitación de la enfermedad.

Esta nueva perspectiva biopsicosocial, integradora, implica la necesidad de un abordaje interdisciplinar en la comprensión de los procesos patológicos y ha suscitado líneas de investigación en las que se ha intentado clarificar qué pasa en la «caja negra", en lenguaje skinneriano; o dicho de otra forma, de qué manera influyen las variables psicológicas en la disfunción de los sistemas biológicos. La delimitación de los mediadores biológicos entre la experiencia psicológica y la enfermedad requiere la cooperación entre la psicologia, la neurologia, la endocrinologia, la inmunología, la bioquímica... En los apartados siguientes abordaremos algunos de los resultados más relevantes de esta cooperación interdisciplinar.

También quisiéramos recordar que este enfoque ha recibido apoyo en el campo de la psicología clínica. Por citar un ejemplo significativo, Beck (1983) apunta que los fenómenos psicológicos y bioquímicos en la depresión son simplemente caras diferentes de la misma moneda, calificando de reduccionista la idea de que los primeros son causa de los segundos o viceversa ${ }^{2}$.

Aunque el cáncer no ha sido considerado como enfermedad psicosomática según el enfoque clásico, hay recogidas observaciones muy antiguas (tan antiguas como Hipócrates o Galeno) sobre su posible relación con variables psicológicas. Muchas de estas observaciones surgieron de la experiencia clínica médica con casos concretos de la enfermedad (e.g., Parker, 1885). Diversos estudios recientes, con animales (e.g., Riley et al., 1981) y con seres humanos (e.g., Grossarth-Maticek et al., 1982), aun con enormes lagunas metodológicas, como veremos, siguen sugiriendo la existencia de una participación de factores psicosociales en la vulnerabilidad a la enfermedad y en su evolución o pronóstico. Este creciente interés suscitado en las últimas décadas por la relación entre psicología y cáncer y sus mediadores biológicos, proviene en buena parte del contacto cotidiano de oncólogos clínicos con pacientes de cáncer (e.g., Stoll, 1979, 1. parte). Prnsamos que la psicología puede y debe aportar su granito de arena en la compresión de la enfermedad en general y de ésta en particular, llevando a la práctica la orientación interdisciplinar y de consideración del ser humano desde un punto de vista molar que defendemos en este escrito.

\section{FACTORES PSICOSOCIALES Y ENFERMEDAD}

Como ya hemos apuntado, la medicina convencional tiende a descartar el papel de las variables psicológicas en los trastornos somáticos, alejando sus explicaciones de un nivel molar, es decir, del individuo enfermo, para centrarlas en elementos, moléculas o tejidos de ese mismo individuo. Sin embargo, datos como, por ejemplo, los 
proporcionados por la investigación sobre el efecto placebo (e.g., Shapiro y Morris, 1978) o el biofeedback (e.g., Carrobles, 1982) vienen a demostrar que los factores psicológicos, a través del sistema nervioso central, ejercen un control sobre el organismo mucho más profundo de lo que pudiera pensarse. Por otra parte, algunas enfermedades físicas pueden considerarse estructurales, pero la mayoría de las patologías son, por el contrario, desórdenes regulatorios (e.g., enfermedades cardiovasculares, artritis, dolor crónico, alcoholismo, etc.). Siendo el SNC el principal sistema regulatorio del organismo, no es descabellado atribuirle una participación fundamental en el desarrollo y mantenimiento de esas patologías (Cunningham, 1982).

\section{El estrés}

Los «factores psicosociales» a los que se refiere el título del apartado principal, es lo que en la mayor parte de las investigaciones sobre el área se ha venido considerando como estrés. Debido a que la definición de este término se ha centrado unas veces en los aspectos estimulares, otras en los de la respuesta y otras en elementos interactivos, se ha convertido en una especie de pesadilla semántica (Burchfield, 1979; Selye, 1983) que cada investigador define como puede en su momento. En la mayoría de las investigaciones que han estudiado su relación con la enfermedad se ha considerado como estrés a las consecuencias fisiológicas de la exposición del organismo a estimulación aversiva o nueva (e.g., Riley, 1975; Palmblad et al., 1979). Pero una definición más amplia, derivada de los modelos pioneros de Cannon (1929) y de Selye (1936, 1983), sería la de cualquier circunstancia (estimulo estresante) que provoca: a) una alteración en los procesos homeostáticos, y b) la puesta en marcha consiguiente de los mecanismos adaptativos necesarios para restablecer la normalidad (respuesta de estrés). De esta definición se desprende que el estímulo estresante puede ser tanto positivo como negativo (Holmes y Rahe, 1967) y tanto fi- sico como psíquico (véase la discusión de Rogers et al., 1979, sobre la relatividad de esta distinción). La idea de Selye de que la respuesta de estrés es inespecífica ha sido criticada: según Mason (1971) diferentes tipos de estrés provocan distintas respuestas hormonales también. Por otra parte, el que se produzca y la forma en que se produce la respuesta de estrés, según algunos autores (e.g., Lazarus, 1966) viene determinada por la interpretación que hace el sujeto del estímulo más que por el estímulo en sí. En otras palabras: un estímulo es estresante cuando el sujeto lo interpreta así. Son varios los datos, en animales (e.g., Sklar y Anisman, 1979) y humanos (e.g., Frankenhauser, 1975) que indican que la capacidad real o percibida por el individuo para enfrentarse al estrés puede ser un poderoso modulador de la respuesta fisiológica ${ }^{3}$, pero en nuestra opinión esta idea debe contemplarse como una hipótesis provisional, no como un hecho definitivo, como podremos ver más adelante. No obstante, no parece poder mantenerse una definición reduccionista de estrés como respuesta inespecífica y única. Más bien, se puede considerar que el estrés abarca una serie de respuestas fisiológicas diferentes que surgen ante diversos estímulos y que pueden estar moduladas por diversas variables. Dada esta variabilidad, tanto en las características de la situación estresante como del sujeto,, no obstante, existe, al parecer, en todas las especies animales con sistema adrenocortical (Burchfield, 1979), un núcleo básico de cambios inducidos por el estrés que caracterizarían, por una parte, lo que Cannon (1929) describió como respuesta de "lucha o huida", y por otra lo que Selye (1936) definió como "Sindrome General de Adaptación", y que vamos a explicar brevemente a continuación.

La percepción de una situación como estresante (nueva o amenazante) produce en el individuo que la percibe como tal, una serie de efectos neuroquímicos (Anisman y Sklar, 1982), hormonales (Curtis, 1979) e inmunológicos (Solomon et al., 1979). La respuesta hormonal y sus efectos inmunológicos han sido los elementos 
mejor estudiados del proceso. Esta respuesta se inicia en el hipotálamo, que ha sido informado por el córtex cerebral (interpretador del estímulo) y que informa a su vez a la pituitaria para que secrete la hormona adrenocorticotrópica (ACTH). Esta hormona es la encargada de estimular el córtex adrenal, que secretará corticosteroides, fundamentalmente cortisol en el ser humano y primates superiores, y corticosterona en otras especies animales. La médula adrenal, por su parte, estimulada directamente por el hipotálamo, producirá catecolaminas, epinefrina en especial. Este aumento del nivel de catecolaminas y corticosteroides en sangre desencadena en roedores profundos efectos inhibitorios sobre el sistema inmunológico: produce a) una disminución de los linfocitos circulantes, b) involución del tipo (órgano en el que se producen los linfocitos $\mathrm{T}$ y c) una pérdida correspondiente de la masa de tejido del bazo y de los nódulos linfáticos periféricos (Riley et al., 1981). Con respecto a la especie humana no hemos encontrado en la literatura datos claros sobre el efecto inmunosupresor de dosis fisiológicas de las hormonas y sustancias asociadas al estrés, pero sí existen varios estudios en los que se aprecia la disminución de varias medidas inmunológicas, independientemente de cambios endocrinos, después de la exposición a estrés experimental (e.g., Palmblad et al. 1979) y natural (e.g., Bartrop et al., 1977).

La idea de que las respuestas cognitivas, emocionales y conductuales, y su interacción, pueden terminar influyendo sobre el sistena inmune, provocando una inmunodeficiencia adquirida y transitoria, ha sido el motivo de que la psiconeuroinmunología, una disciplina límice entre la psicología, la neurología, la endocrinología y la inmunología, se esté desarrollando tan rápidamente (Ader, 1981b).

\section{El sistema inmunológico}

$\mathrm{El}$ sistema inmune es el reponsable de mantener la integridad del organismo frente a sustancias extrañas tales como bacterias, virus, tejidos u órganos trasplantados, y neoplasmas. Su tarea, así pues, es doble: por una parte la de reconocer a los elementos extraños al organismo como tales, y por otra la de eliminarlos (Rogers et al., 1979). Para llevar a cabo esta función consta de dos grandes componentes: el humoral y el celular. Las reacciones inmunes humorales son las debidas a los anticuerpos o inmunoglobulinas (hay al menos cinco identificadas: $\operatorname{IgA}$, IgG, IgM, IgE e IgD), sustancias producidas por los linfocitos $B$, una clase de leucocitos producidos a su vez en la médula ósea. La función protectora principal de la respuesta inmune humoral es ante las infecciones bacterianas, pudiendo convertirse en patológica, como en el caso de la alergia, el asma o los de órdenes autoinmunes.

La inmunidad celular es en la que se encuentran implicados principalmente los linfocitos $T$, los macrófagos y los NK. Los primeros son los producidos en el timo, $y$ participan sobre todo en los procesos de hipersensibilidad demorada, reacciones inmunes a tejidos trasplantados, infecciones virales o producidas por hongos, algunos fenómenos autoinmunes, y defensa inmune contra neoplasmas. Los macrófagos se producen en la médula ósea, al igual que los linfocitos B, y la función fundamental en la que intervienen es en la fagocitosis. Apenas hace diez años que se ha descubierto otro tipo de linfocitos, los $N^{4}$, que al parecer adquieren propiedades citotóxicas de forma espontánea, y que están implicados en la defensa contra el desarrollo de infecciones virales y de tumores (Heberman y Holden, 1979).

\section{Relaciones entre el SNC y el sistema inmunológico}

Son diversas las líneas de investigación que han demostrado que el sistema nervioso central puede influir sobre la reactividad inmunológica (Ader, 1981a; Fauman, 1982). En una primera se han demostrado, por una parte, los efectos de diversas variables psicosociales sobre la vulne- 
rabilidad a diferentes enfermedades que implican una mediación inmunológica (Jemmott y Locke, 1984), y por otra, los efectos negativos del estrés sobre medidas inmunológicas concretas, en animales (Monjan, 1981) y en seres humanos ( $\mathrm{Palm}$ blad, 1981). Una segunda línea la constituirían las pruebas de que existen vínculos anatómicos (Williams et al., 1981) y funcionales (Stein et al., 1981) directos entre ambos sistemas. La influencia del cerebro, $y$ en especial del hipotálamo sobre el sistema inmune ha sido estudiada y revisada ampliamente en la literatura (Stein et al., 1979). Una tercera línea de investigación sorprendente que demuestra el control cortical sobre el sistema inmune se refiere a los estudios de condicionamiento de una respuesta inmunológica en ratas mediante paradigma clásico (Âder y Cohen, 1975).

Así pues, parece haber una cantidad considerable de datos que apoyan la existencia de vínculos entre el sistema nervioso y el sistema inmune, directos o a través del eje endocrino: Hipotalámico-Pituitario-Adrenal (Levy, 1982, prefacio).

\section{Estrés, sistema inmune $y$ enfermedad}

La literatura está plagada de datos clínicos y experimentales que ponen en relación la experiencia psicológica con la aparición y el desarrollo de enfermedades (e.g., Amkraut y Solomon, 1975; Rogers et al., 1979; Jemmott y Locke, 1984). Por ejemplo, la influencia del estrés producido por los cambios de vida sobre la aparición de la enfermedad es un hecho bastante aceptado (e.g., Rabkin y Struening, 1976), a pesar de los problemas metodológicos inherentes a la investigación de esta relación (véase más adelante). Sin embargo, estamos muy lejos de conocer perfectamente los mecanismos biológicos a través de los cuales la experiencia subjetiva del estrés se puede traducir en los cambios patológicos que conducirán a la enfermedad. Este es el punto que vamos a intentar desarrollar brevemente en este apartado. La razón de que nos centremos en el sistema inmune se debe al papel que parece desempeñar en la defensa del organismo frente al desarrollo de tumores.

Es evidente que no en todas las patologías interviene el sistema inmunológico. Este es el caso de las enfermedades cardiovasculares, y sin embargo también sobre ellas parecen ejercer las respuestas fisiológicas asociadas al estrés un efecto pernicioso (e.g., Jenkins, 1976). Esto sugiere que el estrés podría en unos casos influir directamente sobre la producción de patologías, a través de la activación de la rama simpática del sistema nervioso autónomo, y de la médula de las glándulas suprarrenales, favoreciendo por ejemplo el desarrollo de arteriosclerosis, hipertensión o enfermedades de los vasos coronarios, mientras que en otros casos esta influencia se produciría indirectamente, es decir, a través de la disminución de la competencia inmunológica (Riley, 1981, nota 31), afectando la vulnerabilidad a enfermedades en las que ésta esté implicada, como parece ser el caso de las neoplasias. Para Chesney y Rosenman (1983), y de acuerdo con el modelo de Henry y Stephens (1977), la diferencia entre ambos tipos de influencia podría depender de la controlabilidad por parte del sujeto de la siruación estresante. En una serie de experimentos con animales, Henry y Stephens (op. cit.) demostraron que cuando se le da la oportunidad de ejercer un control sobre la situación, el organismo responde con actividad y agresión y con una activación simpática-medúlo-adrenal (la respuesta de "lucha o huida" descrita por Cannon). El patrón de respuesta, cuando la situación tiene características de incontrolabilidad, se parece, por el contrario, al descrito por Selye, esto es, de activación adrenocortical. Chesney y Rosenman citan también los estudios de Frankenhauser (1975, 1980) con resultados semejantes. Que los efectos patológicos del estrés (potenciadores del proceso de enfermedad) están mediatizados por variables relacionadas con la situación estimular (como su cronicidad, tipo, control que permite, etc.) y con el propio sujeto (experiencia previa, capacidades de enfrentamiento, etc.), ha sido 
una idea repetida por otros muchos autores (e.g., Mason, 1975; Lazarus, 1976; Sklar y Anisman, 1981; Locke y Kraus, 1982).

Ahora cabe preguntarnos cuándo afecta la acción del estrés al sistema inmunológi$\mathrm{co}$, influyendo por consiguiente indirectamente sobre la producción del proceso patológico. Parece que el sistema inmune se ve dañado principalmente a través de la activación adrenocortical. Decimos principalmente porque también las catecolaminas pueden ejercer un panel inmunosupresor (Borysenko y Borisenko, 1982). A pesar de la importancia de la especificación de la función de este mediador biológico (competencia inmunológica) en la relación estrés-enfermedad, son relativamente pocos los estudios en los que se ha investigado la influencia del estrés sobre la inmunidad humana (vid. revisión de Locke, 1982, sobre investigación en humanos, y Monjan, 1981, en animales). Una razón principal de este estado de cosas es que, mientras que en la investigación con animales el estrés puede definirse operativamente, cuantificarse y manipularse, al menos hasta cierto punto (Riley et al., 1981, Newberry, 1981), en la investigación con seres humanos existe una limitación inherente en la utilización de diseños experimentales, lo que ha obligado el uso de condiciones estresantes naturales, como por ejemplo la muerte de un ser querido (Bartrop et al., 1977; Schleifer et al., 1983), el ser sometido a una operación quirúrgica (Pees, 1977), pasar exámenes (Dorian et al., 1981; Kiecolt-Glaser, 1984), cambios de vida (Locke et al., 1978), etc. A Palmblad y sus colegas (1979; vid. Palmblad, 1981) se debe una de las pocas investigaciones psicoinmunológicas experimentales con seres humanos; en ella han utilizado la deprivación de sueno y ruido como estresores.

Según se desprende de la mayor parte de los estudios en humanos, tanto los estresores experimentales como los que se dan de forma natural, tienden a tener efectos inhibitorios sobre la inmunidad celular, resultado que no se repite tan claramente en el caso de la inmunidad humo- ral (Locke, 1982). Un dato repetido también es el de la influencia diferente del estresor según las estrategias de enfrentamiento de los sujetos. Locke y Kraus (1982) citan varios estudios al respecto. Así, por ejemplo, en el estudio de Locke et al. (1978), los estudiantes a los que se consideró con menor capacidad de enfrentamiento al estrés mostraron una actividad NK significativamente menor que el resto de sus compañeros. De todas formas, las críticas fundamentales que se tienen que hacer a trabajos psicoinmunológicos como el de Locke et al., se centran, como veremos al referirnos directamente al cáncer, en la propia evaluación psicológica, y en especial si se trata de un estudio retrospectivo (el de Locke et al. lo es): ¿cuándo se considera un acontecimiento como estresante?, ¿y una estrategia de enfrentamiento como adaptativa? $Y$ en cualquier caso, ¿es fiable el autoinforme del sujeto de lo que le ocurrió o lo que sintió hace seis meses, pongamos por caso? Estas consideraciones nos parecen fundamentales a la hora de inferir con una cierta seguridad cualquier posible relación entre variables psicosociales y la susceptibilidad a enfermar (vid. apartados siguientes).

\section{FACTORES PSICOSOCIALES Y CANCER}

La caracteristica definitoria de las células neoplásicas o cancerosas es la de su capacidad para reproducirse de forma incontrolada, invadir tejidos normales y metastatizar en lugares distantes del organismo, independizándose de los mecanismos normales inhibidores de la mitosis.

Son tantas las causas posibles de que un ambiente celular desarrolle propiedades cancerosas que lo apropiado sería considerar la fase de iniciación o transformación al igual que la de promoción (crecimiento y desarrollo de metástasis) como un proceso multifásico y multifactorial (e.g., Day y Brown, 1980). En el origen del cáncer pueden intervenir miles de factores que 
para mantener la terminología convencional pueden denominarse endógenos (e.g., genéticos, hereditarios o no) y exógenos (carcinógenos químicos, radiactivos, víricos, etc.), que por supuesto interactúan de forma compleja y completamente desconocida en muchos casos todavía. Observaciones como la de la existencia de una gran variabilidad en el desarrollo de cánceres entre individuos sometidos a dosis aparentemente similares de carcinógenos (e.g., Doll, 1977), asi como la considerable variabilidad individual en la evolución de la enfermedad (e.g., Rogentine et al., 1979), son las que han contribuido al interés por la intervención de variables psicosociales en el proceso. La pregunta a la que se pretende contestar es en qué medida o de qué forma, podrían factores psicosociales (en esa concepción multifactorial del origen de la enfermedad) potenciar o inhibir la acción de uno o varios de esos agentes, actuando como un agente más en la fase de transformación o, una vez que se ha producido la transformación neoplásica, aumentando o disminuyendo la vulnerabilidad del organismo al desarrollo del tumor.

Comenzaremos nuestra discusión analizado la información proporcionada por la investigación realizada con animales. Las ventajas de utilizar modelos animales en este área son obvias dadas las dificultades de obtención e interpretación de datos en el ser humano, aunque las desventajas también son evidentes cuando se trata de hacer inferencias en relación con la especie humana. Los estudios con animales, además de permitir un mayor control metodológico en todos los sentidos, pueden servir para seleccionar predictores específicos estudiables después a nivel humano. A continuación revisaremos, intentando poner orden en el ambiente bastante caótico reinante, la investigación llevada a cabo con seres humanos en la que se han puesto en relación variables psicológicas con la aparición y desarrollo del cáncer. También expondremos el estado de conocimiento de las posibles vías de influencia biológicas que se han sugerido entre estos dos grupos de variables.

\section{Investigación con animales}

Las experiencias realizadas para estudiar la influencia del estrés sobre el cáncer en animales se han desarrollado principalmente a partir de los años cuarenta y se han caracterizado por el uso de roedores. La elección de estos animales se ha debido, entre otros factores, a la posibilidad de desarrollar razas puras, a la rapidez de aparición de los tumores (pueden desarrollarse en meses) y a que su fisiología no es muy diferente a la de los humanos, $y$, en muchos casos, idéntica (Fox, 1981).

Las primeras investigaciones se interesaron por la influencia de las diferentes temperaturas ambientales en la aparición de los tumores espontáneos (Wallace et al., 1942), o por los efectos de la descarga eléctrica (e.g., Reznikoff y Martin, 1957), obteniéndose resultados contradictorios. Este problema, que se mantuvo en las siguientes décadas dio pie a La Barba para comentar en 1970 , que la confusión reinaba en la literatura. Desgraciadamente, catorce años después no estamos en condiciones de ser demasiado optimistas. Sin embargo, intentaremos remontar nuestras respuestas emocionales y revisaremos ahora este campo presentando breves descripciones de las características de la historia de los sujetos, de la variable independiente (el estrés), de la variable dependiente (el tumor) y los problemas que las afectan. Destacaremos después, los resultados obtenidos acerca de la influencia del estrés en el tumor según la etapa de desarrollo del mismo y finalizaremos con algunas conclusiones.

\section{A) Historia de los sujetos}

Según hemos podido comprobar en reiteradas ocasiones, una de las razones que pueden explicar los resultados contradictorios ha sido la falta de control de las distintas variables relacionadas con la historia de los sujetos. Por este motivo, queremos senalar algunas de ellas que han recibido menos atención.

a) Por lo que se refiere a las variables 
genéticas, no se han tenido en cuenta, en algunas ocasiones, los atributos genéticos, los niveles hormonales y la función del sistema inmunológico, pudiendo diferir estas características entre las distintas razas, siendo posible que este hecho altere la vulnerabilidad de los sujetos al cáncer experimental (Fox, 1981).

b) Por otro lado, debemos recordar que un gran número de cánceres espontáneos son de origen vírico. Estos agentes (conocidos o sospechados) pueden estar actuando en el organismo, y, si no se someten a control, su influencia puede confundir a los investigadores (Riley et al., 1981).

c) Variables evolutivas como el peso y la edad de los roedores pueden correlacionar con la tasa de carcinogénesis teniendo que ser sometidas éstas a control riguroso (Fox, 1981).

d) La situación ambiental que mantienen los sujetos desde su nacimiento es fundamental a la hora de extraer conclusiones; Riley se ha preocupado mucho por este tema, señalando con gran detalle y precisión las características ambientales que influyen en las respuestas de los sujetos (distinguiendo entre medio ambiente protector y medio ambiente estresante), haciendo hincapié en variables tales como alimentación, olores, ruidos, feromonas circulantes, corrientes de aire, polvo, ventilación, temperatura, luz, características de diseño de las jaulas, componentes de las mismas, cercanía de jaulas de machos y de jaulas de hembras, etc. (ver con más detalle en Riley et al., 1981). Estas indicaciones son de gran importancia para aislar el efecto de la variable estresante y no contaminar los resultados con variables extrañas no controladas. Este autor recomienda el diseño concreto y cuidadoso de un hábitat protegido, con el fin de controlar los efectos de toda fuente extraña de estrés que pudieran confundirse con los producidos por la condición experimental.

\section{B) El estimulo estresante como variable independiente}

Empezaremos recordando que ya hemos comentado la polémica existente en la literatura acerca de la definición de "estrés». Una definición dada por uno de los investigadores más representativos es la de «cualquier variable que provoca cambios bioquímicos y celulares específicos, inducidos por una activación del córtex adrenal» (Riley et al., 1981, pág. 31).

Sólo señalaremos aquí que para algunos autores los sucesos estresantes por sí mismos no son un factor de riesgo para el cáncer. Más bien es la incapacidad para enfrentarse con el estrés de una forma adaptativa la que puede alterar el medio ambiente interno para favorecer el desarrollo de tumor (Sklar y Anisman, 1981). Después comentaremos esta definición, pero adelantaremos que debe considerarse aún provisional.

Analicemos la estimulación estresante que puede dividirse de la siguiente forma:

a) En cuanto al tipo de estimulación, podemos distinguir entre estrés procedente del hábitat del sujeto y estrés experimental, por un lado, y estrés físico versus estrés social, por otro.

b) En cuanto a la intensidad, diferenciaremos entre estrés leve y estrés severo (desgraciadamente no hay definiciones operativas de estos dos términos).

c) En lo que respecta a la duración, se puede clasificar el estrés como crónico o agudo.

d) Por lo que se refiere a la capacidad de enfrentamiento de los sujetos, el estrés puede ser controlable o no controlable.

$\mathrm{Ya}$ hemos comentado la necesidad de distinguir entre estrés ambiental del hábitat del sujeto y estrés experimental. Detallaremos ahora los estresores físicos y sociales más utilizados:

Estresores físicos: descarga eléctrica, nadar en agua fría, sonidos, temperatura ambiental (alta o baja), inmovilización física, rotación o transporte de la jaula, exposiciones a depredadores, presentación de luces de baja o alta intensidad, oscuridad, infecciones provocadas y reclusión entre otros.

Estresores sociales: aislamiento, hacinamiento, desorganización social, separación intermitente de la madre, manejo, etcétera.

En cuanto a la intensidad, no hay con- 
senso entre los autores. Por ejemplo, algunos pueden considerar la rotación como un estímulo leve, mientras que otros la interpretan como un estímulo intenso. Esto dependerá, entre otras cosas, de la historia ambiental del sujeto (medio protegido o estresante).

Por otro lado, cualquier estresor físico o social puede aplicarse con distintas duraciones o intensidades, pudiendo ser controlables o no. Asimismo, se pueden dispensar en diferentes momentos (antes, durante o después de la implantación o inducción del tumor), siendo esta variable temporal de relevancia primordial para analizar los efectos del estrés.

\section{Problemas que se presentan}

1. Algunas definiciones de los tipos de estímulos no son operativas. Por ejemplo, Sklar y Anisman (1981) definen el estrés agudo como una sola aplicación del estímulo y, sin embargo, a veces encontramos que se denomina estrés agudo a la aplicación de 60 descargas en una misma sesión (Sklar y Anisman, 1981). Igual sucede con la diferencia entre estímulo leve o intenso, como ya hemos indicado. En consecuencia, la ambigüedad de las definiciones puede impedir, de alguna forma, una clarificación de las relaciones funcionales precisas entre el tipo de estimulación y sus efectos.

2. En algunos autores, parece más importante la cronicidad de la estimulación que su momento de aplicación con respecto a la fase de desarrollo del tumor, sin un control suficiente de esta última variable temporal. Este control es necesario como se ve en los dos trabajos siguientes.

En el primer experimento, Riley et al. (1981) inoculan un corticosteroide sintético potente (FCA) que simula los efectos celulares y bioquímicos que provoca el estrés fisiológico, después del transplante del linfosarcoma $6 \mathrm{C} 3 \mathrm{HED}$, en distintos momentos del desarrollo del tumor (en los días $7 .^{\circ}, 14,21$ y 28 después del trasplante). Se encuentran los siguientes efectos: a) En el 7." día el FCA aumenta el crecimiento del tumor; b) En el 14 día disminuye el efecto del FCA y la tasa de crecimiento es menor que en la aplicación del 7." día; c) En el 21 día disminuye aún más el efecto del FCA (el aumento es menor que en la aplicación del 14 día); d) En el 28 día el FCA no produce efectos sobre el crecimiento del tumor. Es decir, la fase del desarrollo del tumor durante la que se aplica el estrés es de gran importancia para explicar los efectos que se obtienen. Este hecho, según los autores, puede depender del número de células tumorales viables que permanecen en el organismo en el momento de la administración del estresor (cuanto más tarde se aplique, menos células tumorales viables existirán en el organismo $y$, en consecuencia, el estresor tendrá menos efectos sobre el desarrollo del tumor) (Riley et al., 1981, págs. 66 a 69). Creemos que este experimento está bien disenado y presenta definiciones operativas de las variables que controla, así como tiene en cuenta variables muy pertinentes de la historia de los sujetos.

En el segundo trabajo, Sklar y Anisman (1981) aplican descarga eléctrica no controlable aguda y crónica utilizando un mastocitoma singénico (tumor histocompatible) como variable dependiente. El estresor se presenta de diferentes formas:

a) Una sola aplicación (estrés agudo) 24 horas después del trasplante del tumor, dando como resultado un aumento considerable de su desarrollo; b) La descarga se

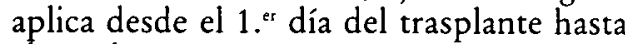
el $50^{\circ}$ día (estrés crónico), teniendo como consecuencia que el aumento del desarrollo del tumor es muy pequeño; c) La descarga se presenta desde el primer día del trasplante hasta el décimo día (estrés crónico), no produciendo ningún aumento del tumor y el tamaño del mismo llega a ser menor que el de los controles. Este hecho los autores lo consideran como una inhibición del desarrollo del tumor. Las conclusiones que extraen son que «el antagonismo que se encuentra entre los efectos del estrés agudo (que aumenta el desarrollo del tumor) y del crónico (que lo inhibe) es fiable, y no parece ser una conse- 
cuencia de la fase de desarrollo del tumor" (pag. 378).

El experimento está bien diseñado, pero, a nuestro juicio, estas conclusiones no pueden extraerse de este trabajo, ya que los autores no aplican el estresor crónico sólo en un momento determinado de la fase de desarrollo del tumor, sino que lo administran de forma continuada durante cinco o diez días, debido a que el estrés debe ser crónico. En consecuencia, pensamos que no pueden saber si el efecto es debido a la cronicidad del estresor o al momento del desarrollo del tumor. Por lo tanto, la interpretación de Riley parece más coherente con los datos que obtiene. Como veremos después, parece que Sklar y Anisman se acercan a la tesis de Riley en 1982 (influencia del momento de aplicación), aunque siguen considerando muy relevante la distinción entre agudeza o cronicidad del estresor. De cualquier forma, queremos recordar que los dos experimentos utilizan distintos tipos de tumor y de estresor y animales de diferentes razas y con historias distintas, y esto puede afectar los resultados. Este problema lo encontraremos con demasiada frecuencia siempre que queramos comparar resultados de investigaciones de diferentes autores.

3. Incluso en términos fisiológicos, la intensidad del estresor puede presentar problemas, puesto que exposiciones repetidas al estrés pueden hacer que las respuestas se adapten, siendo posible que la «intensidad funcional» de esta estimulación cambie por el tiempo (Riley et al.1982; Newberry, 1981). Durante una exposición a un estrés experimental crónico pueden darse fenómenos inmunológicos bifásicos, alternándose la inmunosupresión con un aumento de la inmunocompetencia (Monjan y Collector, 1977; Riley et al., 1982). Esto puede explicar, en parte, algunos resultados contradictorios. Creemos que este dato, como tantos otros, no deben olvidarse a la hora de inferir al campo humano.

4. Como vimos antes, la intensidad del estímulo presenta problemas especificos, puesto que para algunos autores el es- trés leve inhibe el crecimiento del tumor (Turkevich, 1960), mientras que para otros lo aumenta (Henry et al., 1975).

5. Los complejos afectos de los factores temporales (aplicación del estresor antes, durante o después de la inducción o trasplante del tumor) pueden tener consecuencias específicas, que pueden alterar los resultados (e.g., Newberry, 1981; Amkraut y Solomon, 1972).

6. En cuanto a la influencia de la controlabilidad parece ser, como veremos más adelante, que en gran parte de los trabajos se concluye que un estímulo controlable no tiene efectos sobre el desarrollo del tumor (Sklar y Anisman, 1979) mientras que un estímulo no controlable tendrá diversos efectos según otras características estimulares como la temporalidad o la duración (ver Tablas I y II). Nosotros consideramos que debido a la importancia del tema para los psicólogos, este hecho merece algún comentario. Cuando examina los trabajos y las revisiones, el lector puede extraer la conclusión de que la controlabilidad es un hecho fundamental por sí mismo a la hora de explicar los efectos de la estimulación estresante en el desarrollo del tumor. Pero queremos apuntar que no hay datos definitivos acerca del cuál es el papel de esta variable aisladamente, puesto que no hay que olvidar que la interacción de esta variable con otras (las relacionadas con el estímulo, con el tumor o con la historia de los sujetos) preside los efectos sobre el tumor. Mientras que estos índices no se aíslen correctamente, y teniendo en cuenta todos los problemas ya señalados (e.g., la falta de definiciones operativas de estas variables), no recomendamos que el investigador se deje llevar por el gran atractivo que tiene esta hipótesis y dé por hecho algo que todavia requiere mayor apoyo empirico.

7. Pueden darse diferencias entre los distintos tipos de estrés no sólo por su cronicidad, sino también por sus características especiales. Algunos autores encuentran diferencias en los efectos al aplicar en las mismas condiciones distintos estresores físicos (por ejemplo, Nieburgs et al., 1979, encuentran que nadar en agua 
caliente y el transporte de jaulas tienen efectos más persistentes sobre el crecimiento del tumor que la descarga eléctrica).

\section{C) El tumor como variable dependiente}

Los tumores pueden dividirse de la siguiente forma:

a) En cuanto a sus caracteristicas histológicas, podemos distinguir entre tumores alogénicos (incompatibles desde un punto de vista histológico, pudiendo darse rechazo en su trasplante) y singénicos (histológicamente compatibles, no puede darse rechazo).

b) En cuanto al origen, los tumores pueden aparecer de forma espontánea, pueden inducirse por radiación, virus, sustancias químicas u hormonas, o pueden trasplantarse subcutáneamente o por vía intramuscular.

Se da por supuesto que los tumores pueden referirse a distintos tipos de cáncer, aunque los más utilizados han sido los mamarios.

Las variables dependientes más usadas han sido las siguientes: a) Número de tumores; b) Período de latencia de aparición de los mismos; c) Tasa de crecimiento; d) Volumen del tumor; e) Tasa de regresión del tumor; f) Tiempo de supervivencia de los sujetos; g) Medidas fisiológicas o inmunológicas capaces de definir la competencia inmunológica de los sujetos (niveles de corticosterona en plasma sanguíneo, peso del timo, peso adrenal, peso del bazo, número de linfocitos periféricos, etcétera. -Riley et al., 1981-). Como podemos observar, hay que tener en cuenta distintos aspectos a la hora de definir esta variable dependiente, y esto puede provocar muchas complicaciones. Veamos algunas.

\section{Problemas que se presentan}

1. Algunos tumores pueden aparecer o desaparecer de forma espontánea (Fox, 1981).
2. Los resultados serán distintos, dependiendo del sistema y del tipo de tumor utilizado (Fox, 1981).

3. Todavía existen fallos en los accesos a las medidas bioquímicas y celulares (Riley et al., 1982). Esto impide, de alguna forma, que las condiciones de línea base sean las mismas en los diversos estudios.

4. En bastantes experimentos no se han controlado variables ambientales ni otras variables como edad, sexo o raza de los sujetos, que influyen en el desarrollo de los tumores.

5. No existe un consenso generalizado acerca de cuál es la mejor medida de esta variable.

6. Las tasas de desarrollo del tumor son diferentes según sea la forma de inducirlo. Por ejemplo, la carcinogénesis por virus presenta problemas específicos, al igual que la realizada por sustancias químicas.

\section{D) Los efectos de la variable independiente según las diferentes etapas de desarrollo del tumor}

Nos parece interesante presentar los resultados de los estudios, teniendo en cuenta las diferentes etapas de desarrollo del cáncer, puesto que estas fases son una variable importante para analizar los efectos provocados por el estrés, ya que pensamos que la interacción entre la fase de desarrollo y el tipo de estresor es una variable muy pertinente. (Ver revisiones en Sklar y Anisman, 1981; Peters y Mason, 1979, y La Barba, 1970.)

\section{a) Aparición del tumor}

La tabla I presenta los resultados de los experimentos más relevantes de forma sistematizada.

No hemos encontrado datos en la literatura acerca de los efectos de los estímulos controlables, por lo que los datos de la tabla se refieren a estresores no controlables.

Entre los estudios que revelan la inhi- 
TABLA I

Fase de aparición

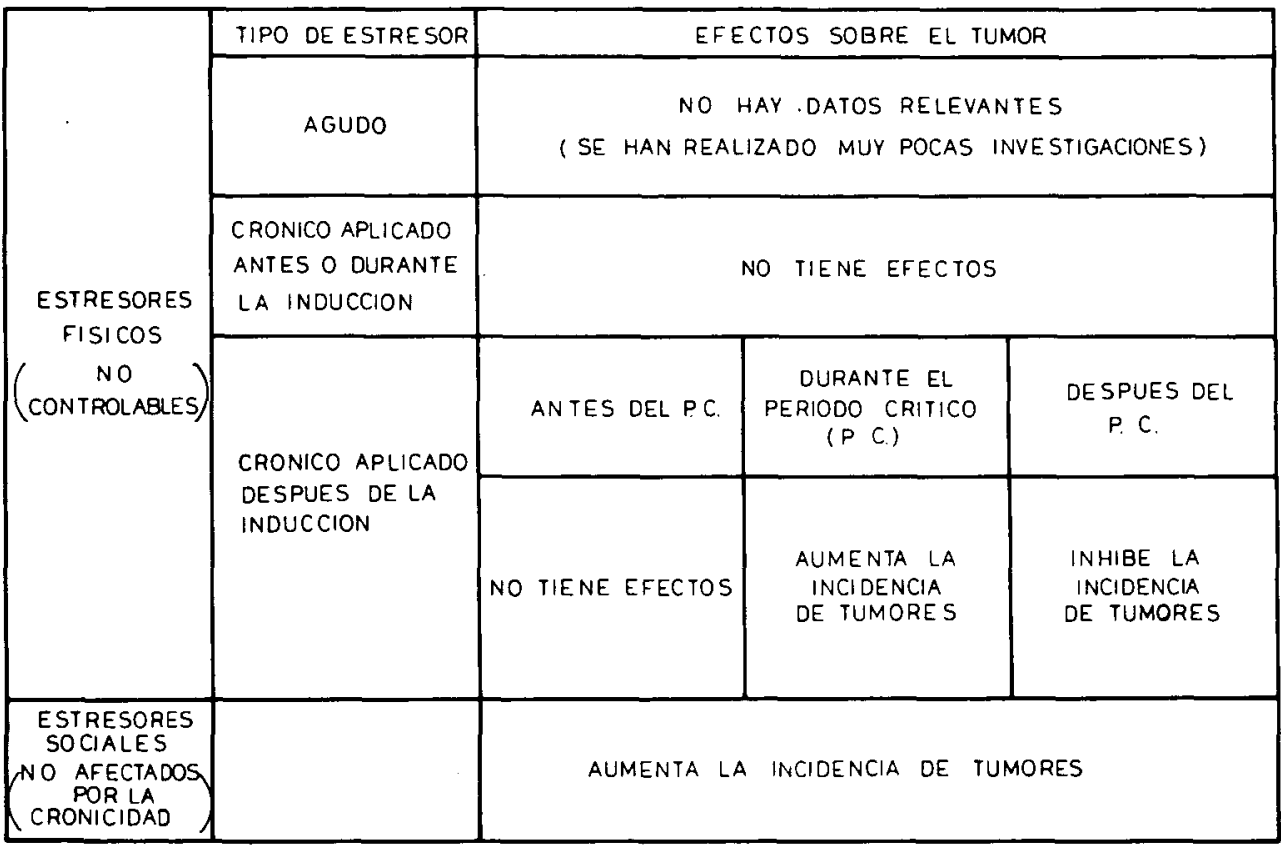

bición del tumor al aplicar un estresor fisico, resaltan los de Newberry (1981), Newberry et al. (1976) y Pradhan y Ray (1974). Por ejemplo, con respecto a los efectos inhibitorios de la reclusión, podemos citar a Ray y Pradhan (1974). Anisman y Sklar (1982) concluyen que los efectos del stresor físico se ven influidos por la cronicidad del mismo. Sin embargo, como observamos en la tabla, parece existir un período crítico, durante el cual el estrés crónico aumentará la incidencia de los tumores, y el estrés administrado antes de este periodo no tendrá efectos que influyan en la carcinogénesis, mientras que el aplicado después provocará efectos inhibitorios (Sklar y Anisman, 1981). En cuanto a la predictibilidad se han encontrado datos que indican que una estimulación estresante crónica, cuando es predecible aumenta la incidencia de tumores espontáneos e inducidos (e.g., Kaversky et al., 1966). El que la influencia de la predictibilidad se produzca siempre en este sentido es, desde luego, una hipótesis provisio- nal. No hemos encontrado experimentos en los que se estudie la influencia de la interacción predictibilidad-controlabilidad en esta primera fase de desarrollo del tumor.

Por lo que se refiere a los estresores sociales, éstos no parecen verse afectados por la cronicidad. Parece que estos estímulos, por ejemplo el aislamiento y la desorganización social y el estrés intermitente de separación de la madre, aplicados en un medio de laboratorio no protegido, tienen como consecuencia el aumento de la incidencia de los tumores (Henry, Stephens y Watson, 1975; Riley, 1975). Pero, de nuevo, hay que tener en cuenta que los distintos sistemas de tumor utilizados pueden contribuir a los efectos apuntados.

\section{b) Fase de crecimiento}

Hemos resumido los resultados obtenidos en la tabla II. 
TABLA II

Fase de crecimiento

\begin{tabular}{|c|c|c|}
\hline \multirow{6}{*}{$\begin{array}{c}\text { ESTRESORES } \\
\text { FISICOS } \\
\left(\begin{array}{c}\text { NO } \\
\text { CONTROLABLES }\end{array}\right)\end{array}$} & TIPO DE ESTRESOR & EFECTOS SOBRE EL \\
\hline & $\begin{array}{l}\text { AGUDO ANTES } \\
\text { DE I. Ó T. (I) }\end{array}$ & INHIBE CRECIMIENTO \\
\hline & $\begin{array}{l}\text { AGUDO DESPUES } \\
\text { DE } 1 . \dot{\mathrm{T}} \mathrm{T} .\end{array}$ & AUMENTO CRECIMIENTO \\
\hline & $\begin{array}{l}\text { CRONICO ANTES } \\
\text { OE I Ó T. }\end{array}$ & $\begin{array}{l}\text { NO TIENE EFECTOS O ANULA LOS EFECTOS DEL ESTRESOR } \\
\text { AGUDO QUE SE APLICA DESPUES DE } 1.0 \text {. } T \text {. }\end{array}$ \\
\hline & $\begin{array}{l}\text { CRONICO DESPUES } \\
\text { DE I. ÓT. }\end{array}$ & INHIBE CRECIMIENTO \\
\hline & ANIMALES & EFECTOS SOBRE EL TUMOR \\
\hline \multirow{2}{*}{$\begin{array}{l}\text { ESTRE SORES } \\
\text { SOCIALES }\end{array}$} & $\begin{array}{l}\text { ANIMALES } \\
\text { ADULTOS }\end{array}$ & AUMENTO CRECIMIENTO \\
\hline & $\begin{array}{l}\text { ANIMALES } \\
\text { INMADUROS }\end{array}$ & EFECTOS INCONSISTENTES \\
\hline \multicolumn{3}{|c|}{ (1) $\begin{aligned} 1 & =\text { INDUCCION DEL TUMOR } \\
T . & =\text { TRANSPLANTE DEL TUMOR }\end{aligned}$} \\
\hline
\end{tabular}

Si analizamos los efectos de los estresores físicos, podemos citar investigaciones que se refieren al estrés físico agudo, señalando que aumenta el desarrollo de los tumores (siempre que se aplique después de la inducción o trasplante del mismo) (Jamasbi y Nettesheim, 1977, y Peter y Kelly, 1977). Riley y colaboradores (1982) argumentan que el estrés físico agudo sólo aumentará el desarrollo del tumor si éste se encuentra, normalmente, bajo el control completo o parcial de los sistemas inmunes de las células $\mathrm{T}$ y $\mathrm{B}$. Anisman y Sklar (1982) rechazan esta afirmación, manteniendo que los resultados que ellos encuentran son fiables, sin aceptar que este tipo de control que pueda tener el organismo sobre el tumor sea el que pueda explicar la posible aparición de estos efec$\operatorname{tos}^{5}$. Por otro lado, para estos autores y también para Seligman (Visintainer, Seligman y Volpicelli, 1983), la habilidad del organismo para enfrentarse con el estrés a través de estrategias conductuales es de una importancia crucial. Presentan experi- mentos donde descargas eléctricas controlables no influyen en el crecimiento del tumor (Sklar y Anisman, 1979), mientras que animales que recibían descarga no controlable desarrollaban tumores de mayor volumen que los controles.

En cuanto a la estimulación no controlable, se ha encontrado que la exposición a estrés físico crónico no controlable parece inhibir el desarrollo del tumor si se produce después de la inducción o trasplante del mismo (Nieburgs et al., 1979; Newberry y Sengbush, 1979; Gershben et al., 1974, y Pradhan y Ray, 1974). Anisman y Sklar (1982) piensan que la inhibición provocada por este tipo de estrés puede deberse en mayor medida al momento de aplicación del mismo, momento que puede coincidir con algún cambio crítico en el desarrollo del tumor (por ejemplo, con la angiogénesis o proceso de vascularización del tumor), que a la cronicidad del estímulo.

Analizando los estresores sociales (no afectados por la cronicidad), encontramos 
que cuando los animales son inmaduros, los resultados son contradictorios: la manipulación y la separación de la madre inhiben el crecimiento de los neoplasmas (Ader y Friedman, 1965; La Barba y White, 1971; Newton et al., 1962) o to aumentan (Ader y Friedman, 1965). Se sugiere que estas diferencias pueden deberse o a la utilización de tumores alogénicos o al período evolutivo en el que se aplica el estresor. No obstante, en la edad adulta, parece que los resultados son más consistentes. Dechambre y Gosse (1973) encontraron que los roedores que vivían en jaulas individuales aumentaban el crecimiento de los neoplasmas trasplantados. Sin embargo, parece que no es el vivir aisladamente lo que provoca este efecto, sino más bien el cambio que sufren los animales cuando son trasladados a otro hábitat, ya que animales que siempre habían vivido en jaulas individuales, cuando se les trasladaba a jaulas colectivas, sufrían igualmente un crecimiento del tumor. Por otro lado, se presenta también un hecho curioso: este crecimiento no se daba entre ratones que "peleaban». Debido a ello, los autores entienden esta respuesta como una conducta de enfrentamiento al estrés que puede disminuir los sucesos neuroquímicos asociados a esta estimulación (Sklar y Anisman, 1981). Estos hechos nos recuerdan que hay que tener en cuenta el contexto de las condiciones sociales del sujeto, intentando utilizar siempre animales con una historia de medio ambiente protegido, observando que incluso en estas condiciones pueden aparecer efectos ambientales insospechados que pueden oscurecer y modificar los efectos tumorigénicos del estrés.

\section{c) Aparición de metástasis}

Parace que se pueden mantener las mismas conclusiones que para la fase anterior. El estrés físico crónico no controlable inhibe la aparición de metástasis, mientras que diversas formas de estrés agudo aumentan la incidencia de las mismas (Fisher y Fisher, 1959; Van Den Brenk et al.,
1976; Saba y Antikatzides, 1976). Siempre hay que recordar que algunos tumores pueden desarrollar metástasis de forma espontánea, al margen de la variable estresante. Por tanto, puede pensarse que el estrés quizás aumente la actividad celular o influya en la capacidad de las células para trasladarse a través de la sangre o de los sistemas linfáticos (Sklar y Anisman, 1981). De todas formas, esta etapa no se ha estudiado con tanta frecuencia como la fase de crecimiento.

\section{E) Conclusiones}

De forma resumida, creemos que éstas pueden ser algunas de las conclusiones más relevantes.

1. El estrés influye en el desarrollo y aparición de los neoplasmas.

2. Según algunos autores el estrés físico agudo no controlable aumenta el crecimiento de los neoplasmas, mientras que el crónico lo inhibe (Anisman y Sklar, 1982).

3. Creemos que el momento de aplicación del estresor es más importante que la duración del mismo.

4. Los estresores sociales no se ven afectados por la cronicidad y si son aplicados en animales maduros parece que aumentan la aparición y desarrollo de los tumores.

5. La hipótesis de que la capacidad de enfrentamiento al estrés es una característica fundamental para explicar los efectos del estresor necesita mayor apoyo empírico.

6. Los resultados han sido contradictorios debido al fallo en el control de variables del sujeto y de la estimulación estresante de relevancia primordial. Riley ha clarificado alguno de los efectos contradictorios que se presentaban controlando cuidadosamente estas variables.

7. La complejidad y variedad de las variables dependiente $\mathrm{e}$ independiente hacen difícil la realización de replicaciones adecuadas, y la ausencia de criterios rigurosos a la hora de llevar a cabo estas replicaciones puede explicar gran parte de los resultados contradictorios. 
8. En consecuencia, no hay datos definitivos que demuestren cuál es el efecto de los estresores en el cáncer experimental, por lo que se necesitan investigaciones mejor controladas.

\section{Investigación con humanos}

La posible influencia de las variables psicosociales (VP) en el origen y desarrollo del cáncer, ya fue considerada por Galeno en el siglo II, cuando señaló que las mujeres melancólicas presentaban con más frecuencia esta enfermedad que las mujeres vitales y optimistas. Durante los siglos XVIII y XIX los médicos observaron que había una posible relación causal entre problemas emocionales y el desarrollo de la enfermedad neoplásica (vid. Snow, 1983; Evans, 1926; Freeman, 1928, y la revisión histórica de LeShan y Worthington, 1956). Durante las décadas 40 y 50 comenzaron los primeros estudios longitudinales. Por ejemplo, en 1946 C. Thomas inicia uno de los trabajos pioneros (Thomas et al., 1979), realizando un estudio epidemiológico con 1.137 estudiantes, en el que utiliza tests psicológicos y cuestionarios para explorar sus relaciones familiares, el estado de su salud, sus hábitos de vida (entre otros) que cumplimentan cada año. Su objetivo es descubrir los factores de riesgo de cinco patologías: enfermedad coronaria, hipertensión, desórdenes mentales, cáncer y suicidio. Inicialmente utiliza el grupo de cáncer como un grupo de control, ya que da por supuesto que esta enfermedad no está relacionada con las VP Sin embargo, en los resultados que califican como sorprendentes y que se presentan en 1973, se observa que, según el Family Attitude Questionnaire, los sujetos del grupo de cáncer parecen presentar un grado menor de intimidad con sus padres en comparación con los otros grupos. Asimismo, se encuentran perfiles psicológicos parecidos entre los sujetos con enfermedad neoplásica y los suicidas. Por otro lado, parece que los cancerosos son poco dados a expresar sus emociones.

Estas primeras investigaciones (vid. re- visiones de Fox, 1978; Morrison y Paffenbarger, 1981; Sklar y Anisman, 1981; Bieliauskas, 1982; Greer y Silberfarb, 1982), tienden a señalar la importancia del componente emocional en la aparición y desarrollo de los neoplasmas. Así, y apoyándose en los primeros trabajos (e.g., Bacon et al., 1952; Rlumberg et al., 1954; LeShan y Worthington, 1955), se establecen hipótesis acerca del posible valor predictivo de la represión emocional, de la negación y de la incapacidad para enfrentarse adecuadamente a la pérdida de una relación emocional importante para el sujeto (Kissen y Eysenck, 1962; Kissen, 1963; Bahnson y Bahnson, 1966; Muslin et al., 1966; Schamale e Iker, 1966; Stavraky et al., 1968). Estos primeros resultados van a marcar la pauta que dirigirá el interés de los investigadores posteriores. A nuestro juicio, estos autores (en su mayor parte de orientación psicoanalítica) realizan un alto nivel de inferencia cuando interpretan sus resultados, presentándose ya serios problemas a la hora de evaluar las primera relaciones encontradas entre las VP y el cáncer.

Como ya hemos comentado, una de las formas de trabajar en este campo consiste en la realización de estudios longitudinales. Pero verdaderamente no se han efectuado muchos. La mayor parte de las veces se ha elegido un criterio retrospectivo. Los resultados de este último tipo de estudios podrian quedar invalidados debido a los serios problemas metodológicos que presentan, muy comentados en la literatura (Fox, 1978; Morrison y Paffenbarger, 1981; Sklar y Anisman, 1981; Borysenko, 1982) y en los que nos detendremos más adelante.

Por otro lado, los investigadores podían interesarse por la posible relación de las VP con la aparición de la enfermedad (en un intento de buscar relaciones causales) o por la influencia de estas variables en el pronóstico de la misma.

En consecuencia, para presentar el campo, los trabajos pueden dividirse en función del enfoque metodológico (longitudinal o retrospectivo) o en base al interés por la aparición o desarrollo del cáncer ${ }^{6}$. 
Sin embargo, el criterio de clasificación más utilizado se ha basado en las distintas VP evaluadas por los investigadores: variables relacionadas con la personalidad $u$ otras características propias del sujeto, o la influencia de diversas situaciones en la vida del mismo, especialmente las "supuestamente" estresantes. Añadimos el adverbio "supuestamente», de acuerdo con Newberry (1981), puesto que, desgraciadamente, con demasiada frecuencia se ha dado por hecho que ciertos eventos eran estresantes para toda la población. Esta circunstancia la analizaremos más adelante, ya que ha sido origen de muchos problemas. Presentaremos el campo ateniéndonos a esta división, pues nos viene impuesta por la literatura, aunque no participemos de ella en todos sus sentidos. Pensamos que este criterio de clasificación adolece de fallos importantes y provoca confusión (por ejemplo, no se sabe bien dónde incluir algunos trabajos y se encuentra que unos autores participan de un criterio, incluyéndolos en el primer grupo de variables, mientras que otros creen que esas mismas investigaciones pertenecen al segundo grupo). Esta confusión se ve favorecida, en parte, por la falta de onerativización de las variables evaluadas. Por otra parte, esta división asume, de forma implícita, que las situaciones estresantes pueden entenderse como una variable del medio ambiente del sujeto, separada de las características propias del individuo. Las autoras de este artículo no comparten esta suposición, pues creemos que se olvida la interacción existente entre el sujeto y su medio.

Otro hecho a resaltar es que estas investigaciones no son experimentales $y$ buscan asociaciones mediante estudios de correlación, en ocasiones sin ningún enfoque metodológico definido (pueden ser estudios descriptivos, sin asumir ningún criterio - ni longitudinal ni retrospectivo-). A veces se intentan inferir relaciones de causalidad, cometiendo, a nuestro juicio, un grave error.

Comentaremos los trabajos más importantes de una forma sistemática, deteniéndonos algo más en algunos de ellos; cuan- do el lector se pregunte por qué dedicamos más espacio a trabajos antiguos, nos gustaría que recordara que estos trabajos han marcado la pauta a seguir durante los años posteriores y hasta la actualidad. Por consiguiente consideramos necesario realizar algún comentario crítico acerca de ellos, con el intento de contribuir al esclarecimiento de los resultados de este campo, pues es necesario que estas líneas de investigación se lleven a cabo con un mayor rigor científico. Para finalizar, presentaremos algunas observaciones críticas y las conclusiones que consideramos más pertinentes. De cualquier manera somos conscientes de que la lectura pueda ser difícil.

\section{A) Variables psicosociales}

\section{VARIABLES DEL SUJETO}

Si se estudia el campo detenidamente, $y$ teniendo en cuenta el modelo de respuesta de Lang (1968), un primer problema que se encuentra con demasiada frecuencia es que no hay una división clara entre variables emocionales, cognitivas y conductuales, y se olvida la interacción que se da entre ellas y, es más, la respuesta emocional (la más atendida) se confunde con las otras dos (Fox, 1978; Wayner et al., 1979). Teniendo esto en cuenta pasaremos a describir en primer lugar las respuestas emocionales más asociadas con la enfermedad neoplásica. Recordemos que la mayor parte de los estudios son retrospectivos.

\section{a) Respuestas emocionales}

Los sentimientos de desesperación y desamparo que están presentes en muchos sujetos que pierden una relación emocional importante (separación, viudedad, divorcio, etc.) han sido asociados con el origen del cáncer (Lombard y Potter, 1950; Murphy, 1952; Schmale e Iker, 1964, 1966; Greene, 1966; Bahnson y Bahnson, 
1966; LeShan, 1966; Horne y Pickard, 1979; Paykel, 1979; ver revisión en Bloom, Asher y White, 1978). En otros casos se han relacionado con un peor pronóstico de la enfermedad (Schmale e Iker, 1966; Ernsterns, 1979). También se encuentran trabajos que no hallan ninguna asociación (Muslin et al., 1966; Schonfield, 1975).

La incapacidad para expresar emociones negativas tales como agresividad no expresada, represión, negación o inhibición, o para modularlas, también se han relacionado con el origen de la enfermedad (Bahnson y Bahnson, 1966, 1969; Kissen, 1966, 1967; Abse et al, 1974; Grissom et al., 1975) o con un peor pronóstico (Stavraky et al., 1968; Derogatis y Abeloff, 1977; Derogatis et al., 1979; Greer et al., 1979). En otras ocasiones, también una expresión exagerada de la ira correlaciona con un peor pronóstico (Greer y Morris, 1975). Estos datos se han interpretado como el resultado de la actuación de los mecanismos de defensa, de los impulsos autodestructivos, de la negación histérica, etc., casi siempre dentro de una orientación psicodinámica. Por ejemplo, Kissen (1966), usando el MPI (Mausdley Personal Inventory) y el EPI de Eysenck, interpreta los datos de los sujetos que obtienen puntuaciones bajas en neuroticismo y altas en la escala de sinceridad como "represión emocional». Eysenck (1983) le critica, apuntando que no se puede extraer esa conclusión sólo a partir de estos índices, considerando conveniente que esta hipótesis reciba un apoyo empírico más fuerte. Por otro lado, partiendo de los mismos datos, podría concluirse que estos sujetos simplemente no presentan las emociones que podrían esperarse normalmente, bien porque nunca las hayan sentido o porque las presenten en una grado menor o distinto que los demás sujetos de la población (Morrison y Paffenbarger, 1981).

\section{b) Variables de personalidad}

El EPI, el EPQ, el MPI y el MMPI han sido los instrumentos más utilizados para medir este constructo psicológico. Los resultados son contradictorios. Por una parte se ha encontrado que la extroversión correlaciona con la enfermedad neoplásica (Coppen y Metcalfe, 1963; Hagnell, 1966; Kissen, 1968). Asimismo, el no neuroticismo también correlacionaba con esta enfermedad (los pacientes de cáncer obtenían puntuaciones significativamente más bajas que los controles en las escalas de neuroticismo) (Kissen y Eysenck, 1962; Kissen, 1964, 1966; Berndt et al., 1980; Eysenck, 1981; Hernández et al., 1984. Por otra parte, Morris et al., 1977, encuentran que pacientes de cáncer de mama presentan un mayor indice de neuroticismo que el grupo de control, según las puntuaciones obtenidas en el EPI; Levendel (1975) y Berndt et al., 1980, no encuentran diferencias significativas en extroversión con pacientes de cáncer de pulmón. Además, Hernández et al., 1984, hallan puntuaciones significativamente inferiores en extraversión en pacientes españolas de cáncer de mama. De igual modo, Rodríguez et al., 1984, no encuentran diferencias significativas ni en neuroticismo ni en extraversión en pacientes españoles de distintos tipos de cáncer.

Eysenck (1983) ha propuesto la teoría del "efecto de inoculación" para explicar las puntuaciones bajas en neuroticismo y altas en sinceridad que parecen presentar los pacientes de cáncer en los trabajos que recoge. Consideramos importante detenernos en ella. Este autor entiende que los neuróticos tienden a no contraer la enfermedad porque están expuestos a un estrés crónico y, en consecuencia, están inoculados a los efectos del estrés, dando por supuesto que los no neuróticos no lo están. Creemos que el autor está dando por sentado algunos supuestos que todavía no se han validado adecuadamente, a saber:

1. El estrés crónico inbibe la aparición $y$ el crecimiento de los neoplasmas. Recoge esta conclusión de la investigación realizada con animales, conclusión que, como ya discutimos anteriormente, no ha sido aceptada por todos los investigadores y que, a nuestro juicio, debe considerarse provisional. Además, es obvio que aún no 
ha sido demostrada en humanos. El autor parece olvidar los problemas que existen para inferir desde los resultados de la investigación en animales (cáncer experimental) al cáncer en humanos, y que Fox (1981) ha estudiado en detalle.

2. Los neuróticos, en sus vidas, se someten a un estrés crónico, luego están inoculados, tendiendo a no contraer la enfermedad neoplásica. Pensamos que no se puede considerar definitivo que los neuróticos presenten menor incidencia de esta enfermedad, ya que los resultados son inconsistentes, necesitándose mayor soporte empírico para aceptar esta conclusión.

3. Los no neuróticos no están expuestos en sus vidas a un estrés crónico. Esta hipótesis está por demostrar.

4. Los no neuróticos contraen más esta enfermedad. Tampoco existen datos definitivos acerca de la asociación entre cáncer y no neuroticismo.

En consecuencia es posible que esta teoría confunda a los investigadores, ya que da por sentadas proposiciones que no han sido aún adecuadamente comprobadas.

\section{c) Depresión}

Nos limitaremos a comentar los trabajos que han medido la depresión con instrumentos psicométricos tales como la escala D del MMPI, el BDI de Reck y la escala de Hamilton. Las puntuaciones altas en estas escalas normalmente se han asociado con el origen de la enfermedad (por ejemplo, Schmale e Iker, 1966, encuentran diferencias aunque éstas no son significativas) o con un peor pronóstico de la misma (Blumberg et al., 1956. Pero, de nuevo, existen datos inconsistentes. Algunos autores no encuentran estas asociaciones (Koenig et al., 1977; Watson y Schuld, 1977; Rodriguez et al., 1984; Plumb y Holland, 1977; Lieber et al., 1976). Otros, como Greer y Morris (1975), hallan puntuaciones bajas en la escala de Hamilton tanto en las pacientes de cáncer de mama como en los controles. Dattore et al., 1980 , encuentran puntuaciones significativamente inferiores en la escala D del
MMPI en pacientes de cáncer comparados con los controles. Barreto et al., 1984, con pacientes españoles hallan correlaciones en depresión, según el BDI, en el grupo de control que no se presentan en el grupo de pacientes de cáncer de mama. Sin embargo, Shekelle et al., 1981, en un estudio longitudinal de diecisiete años, utilizando el MMPI, encuentran un aumento significativo en el riesgo de muerte por cáncer correlacionado con puntuaciones altas en la escala $D$, aunque estos índices no están en el rango de patología.

\section{d) Otras variables del sujeto}

1. Parece que una historia personal de problemas físicos se da más entre los pacientes que no presentan cáncer cuando se comparan con sujetos que tienen la enfermedad (Witzel, 1970).

2. Por otro lado, los pacientes de cáncer que se enfrentan mejor a la enfermedad tienen un índice mayor de supervivencia (Weissman, 1976; Greer y Morris, 1979).

3. Enfermedades como la esquizofrenia presentan correlaciones negativas con la incidencia del cáncer (Bahnson y Bahnson, 1966). Otros trabajos señalan que una historia de enfermedades psicológicas (oscilando entre estados fóbicos leves o agudos y psicosis) se presentaba en un 50 por 100 de los pacientes que retrasaban la primera consulta médica por síntomas de cáncer (Worden y Weissman, 1975).

4. Las creencias de los pacientes también se han evaluado. Por ejemplo, Forner (1984) encuentra puntuaciones significativamente más altas en irracionalidad, según el cuestionario de Ideas Irracionales de McMullin y Giles, en pacientes españoles de cáncer de mama.

\section{VARIABLES AMBIENTALES}

Recordaremos que los sucesos de la vida más estudiados han sido los considerados como estresantes. Ya hemos apuntado algún problema al respecto. Ahondaremos 
más. A la hora de definir qué situación puede ser considerada como estresante para los sujetos, en la mayor parte de los casos se han utilizados las escalas derivadas del SRF (Schedule Recents Experiencies, Hawkins et al., 1957), tal como la escala de Holmes y Rahe (1967), denominada RLCQ (Recent Life Changes Questionnaire), que calculan las unidades de cambio de vida (LCU). Estos instrumentos han recibido serias críticas por su inadecuación para investigar el papel etiológico de los sucesos estresantes en la enfermedad en general (Kasl, 1983; Fauman, 1982). Las dificultades son obvias: se pregunta a los sujetos acercan de su vida pasada y se les evalúa sin tener en cuenta que su recuerdo puede no ser fiable (vid. discusión en Bower, 1981), especialmente en pacientes de cáncer, donde su memoria puede estar afectada por las consecuencias biológicas de la propia patología o por la necesidad de justificar el origen de su enfermedad en base a sus historias personales. Recordemos este comentario y veamos ahora algunos trabajos. Por ejemplo, en las investigaciones de Grissom et al., 1975, se informa de que pacientes de cáncer de pulmón habían sufrido un número importante de situaciones estresantes durante sus vidas. Kissen comparte esta conclusión, y refiere situaciones como pérdida de trabajo o escasa estabilidad en el mismo que se presentan con mayor frecuencia entre los pacientes de cáncer de pulmón (Kissen, 1963). Otros factores como la inestabilidad en la infancia (cambio en la salud de un familiar, cambio de domicilio, de escuela, problemas maritales de los padres, etc.) se han observado en los años anteriores a la aparición de la enfermedad en ninoos (Jacobs y Charles, 1980). Los problemas de la vida del sujeto anteriores a la aparición clínica de la enfermedad (económicos, de cambio de domicilio, de pérdida de trabajo, de enfermedad prolongada de un miembro de la familia, entre otros) también se han asociado con una mayor incidencia de cáncer de mama y de útero. Pero, una vez más, no todos los autores coinciden al respecto. Por ejemplo, Schonfield (1975) encuentra una relación entre sucesos de vida y enfermedad de mama benigna. Muslin et al., 1966, y el mismos Schonfield no hallan asociación entre experiencias de la vida y aparición de cáncer de mama. Pond y Maratos (1977) afirman que un cambio importante en la vida de los pacientes sucedía antes de la aparición de una hipertrofia de próstata benigna, mientras que la aparición del cáncer de vejiga se daba con mayor frecuencia en sujetos que tenían una baja tasa de sucesos estresantes en su vida pasada.

\section{B) Observaciones críticas}

Los estudios retrospectivos han recibido serias crticias en la literatura. Intentaremos comentarlas brevemente.

1. La enfermedad puede estar presente antes y durante los sucesos estresantes que se citan, y las reacciones de los sujetos a estas situaciones pueden estar influidas por la propia enfermedad (Fox, 1978; Sklar y Anisman, 1981).

2. La visión del paciente acerca de su historia pasada puede alterarse por la enfermedad. Recordemos que se considera aparición de la enfermedad al reconocimiento clínico de los síntomas y no debe confundirse con el origen y desarrollo de la misma, ya que algunos tipos de cáncer pueden tardar hasta veinte años en poder ser detectados clínicamente.

3. El diagnóstico conocido o la sospecha del mismo, el ajuste psicosocial a una enfermedad crónica, el miedo al tratamiento o a la aparición de nuevos nódulos, metástasis o a la muerte, pueden causar cambios importantes en las respuestas psicológicas de los pacientes (Borysenko o Borysenko, 1982; Morrison y Paffenbarger, 1981).

4. Los estudios que intentan inferir relaciones de causalidad no cumplen (en su mayor parte) los criterios epidemiológicos establecidos para considerar las variables psicosociales como factores de riesgo (Morrison y Paffenbarger, 1981).

5. Se insiste en la causalidad y se olvida que el objetivo debe estar en la búsqueda de relaciones funcionales. 
Los estudios longitudinales parecen estar mejor preparados para obtener resultados fiables. Sin embargo, existen problemas comunes a gran parte de los trabajos (sean longitudinales o retrospectivos). Expondremos a continuación algunos de ellos:

1. Se echan en falta descripciones operativas de las variables evaluadas. Veamos un caso en particular. Greer et al. (1979), en su interesante estudio prospectivo e interdisciplinario llevado a cabo con pacientes de cáncer de mama, extraen la conclusión de que la supervivencia era mayor entre las mujeres que inicialmente respondían al diagnóstico con negación o con espíritu de lucha, en comparación con las pacientes que presentaban respuestas de aceptación estoica o sentimientos de desesperación y desamparo. Estas últimas tenian una mayor tasa de mortalidad y de metástasis. Pues bien, creemos que se necesitaría una mayor operativización en la descripción de los estilos de respuesta para aumentar la fiabilidad de los resultados. Aunque no debemos olvidar que estos autores representan un buen ejemplo (desgraciadamente muy escaso en la literatura) de intentar poner en relación respuestas psicológicas con respuestas biológicas y enfermedad neoplásica. En uno de estos trabajos, Pettingale, Greer y Tee (1977) se evalúan la expresión de la ira y su relacićn con el nivel de inmunoglobulinas en suero en pacientes de cáncer de mama, ericontrándose que la expresión de la ira no estaba relacionada con los niveles de IgG, $\operatorname{IgM}$ o $\operatorname{IgE}$, pero sí se hallaban niveles significativamente más altos de IgA en las pacientes que inhibian la ira. El estudio es criticable, pero tiene un gran interés por el esfuerzo realizado por medir variables mediadoras, inmunológicas en este caso.

2. En cuanto a las variables de personalidad, no se debe olvidar la polémica sobre la teoría de los rasgos vigente en la Psicología de la Personalidad.

3. También se han olvidado en algunas ocasiones las críticas que han recibido los autoinformes (vid. discusión en Fernández Ballesteros, 1983).

4. A veces, no se han tenido en cuen- ta las diferentes etiologías de los distintos tipos de cáncer ni los factores de riesgo con ellos asociados, como por ejemplo la conducta de fumar (este problema se da en el estudio de Thomas et al., 1979).

5. En otros casos, las evaluaciones psicológicas de los pacientes no han sido ciegas, como en el caso del doctor Kissen, que podía estar influido por el gran número de pacientes de cáncer de pulmón que habia evaluado a lo largo de su historia profesional, presentándose predicciones que llamaremos «contaminadas». Por ejemplo, el estudio semiprospectivo bien controlado de Schmale e Iker (1966) plantea algunos problemas en este sentido. A partir de los resultados obtenidos con mujeres con frotis uterino repetido, que era clasificado como clase III según el método Papanicolaou, se predice el diagnóstico de cáncer en base a la desesperanza expresada ante un suceso de su vida acaecido en los seis meses anteriores a la evaluación de las pacientes. Utilizando el MMPI se identifican correctamente 11 de los 19 diagnósticos de cáncer y 25 de los 32 sin la enfermedad $(p=0.02)$. La evaluación fue ciega en el sentido de que los datos se obtuvieron $y$ se interpretaron antes de que las pacientes, su médico, el patólogo y los investigadores conocieran los resultados histológicos de la biopsia realizada, pero lo cierto es que en la entrevista los autores habían recogido otros datos de las pacientes tales como raza, ciudad de nacimiento, nivel socioeconómico, número de matrimonios y otros síntomas de patología uterina, $y$, en consecuencia, toda esta información de la que disponian podía afectar las predicciones realizadas. En este sentido la evaluación no habría sido del todo ciega (Morrison y Paffenbarger, 1981).

6. En algunos estudios se comparan grupos sin emparejar a los sujetos en índices tan relevantes como edad $y$ nivel socioeconómico.

7. En otros, no se controla la edad de los sujetos cancerosos o se incluyen en el grupo de control sujetos con nódulos benignos, olvidando que esta circunstancia 
puede ser un factor de riesgo para el cáncer.

8. Resulta bastante complicado detectar si el paciente sospecha el diagnóstico. Se ha intentado evaluar esta variable con el Rorscharch (por ejemplo, Bahnson y Bahnson, 1966, sugieren que los pacientes eran conscientes de su enfermedad aunque lo negaran), pero debemos recordar las críticas que este test ha recibido en la literatura psicológica. El no poder detectar este hecho es un factor importante en la evaluación de los efectos de cualquier variable, sobre todo en nuestro país, donde suele ser habitual que el paciente no reciba información acerca de su diagnóstico.

9. En otras ocasiones, los investigadores no ponen en relación sus resultados con los obtenidos por los análisis epidemiológicos de los factores de riesgo de la enfermedad en general. Por ejemplo, el estudio de LeShan (1959) en el que utilizó la pérdida de una relación íntima como variable predictora para el cáncer, con un criterio retrospectivo, pasaba por alto que estudios epidemiológicos realizados en el mismo país en el que investigaba este autor, que habían evaluado tasas de mortalidad en viudos (en comparación con los casados), indicaban que la frecuencia relativa de muerte después de esta pérdida era mucho mayor para otras enfermedades que para el cáncer (Kraus y Lilienfeld, 1959, citado por Morrison y Paffenbarger, 1981).

\section{C) Conclusiones}

1. La mayor parte de los estudios realizados han sido retrospectivos, presentando graves problemas metodológicos que pueden invalidar, en gran medida, sus resultados.

2. La esperanza reside en los estudios longitudinales, bien diseñados, de muestras amplias y largos períodos de seguimiento.

3. En cuanto a las variables psicosociales más citadas entendemos que:

a) Se necesitaría una base más firme para poder concluir que en los pacientes de cáncer se dan con mayor frecuencia pérdidas emocionales importantes a lo largo de su vida y antes de la aparición de la enfermedad.

b) Aunque hay bastantes datos sugerentes de la existencia de una relación positiva entre inhibición emocional y desarrollo del cáncer, en su mayoría proceden de estudios con deficiencias metodológicas que los invalidan en gran medida.

c) La relación entre sentimientos de desesperación y enfermedad neoplásica ha recibido un cierto apoyo, aunque débil y necesita también un mayor soporte empírico.

d) Los estudios prospectivos en general no han encontrado asociación entre depresión (evaluada psicométricamente) y esta enfermedad, salvo en contadas excepciones, pareciendo obvio que ha recibido mayor apoyo empírico la hipótesis contraria.

e) Los resultados derivados de la evaluación de las variables de personalidad son inconscientes, y cualquier teoría (como la del efecto de inoculación de Eysenck) que se basa en ellos debe analizarse con cautela.

f) En consecuencia, creemos que el camino adecuado se halla en utilizar enfoques longitudinales, diseños apropiados y un control riguroso de las variables a evaluar, así como la inclusión de los mediadores biológicos para poder conocer qué tipo de influencias (a nivel neuroquímico, inmunológico, hormonal, etc.) están funcionalmente relacionadas con el estrés o cualquier otra variable psicosocial en humanos.

\section{Posibles mediadores biológicos}

El estado de la investigación de las relaciones entre variables psicológicas y el desarrollo de neoplasmas en el ser humano, que hemos intentado revisar en el apartado anterior, podría servir de justificación suficiente del estudio de los mecanismos biológicos mediadores. Como hemos visto, apenas existen trabajos con humanos en los que se estudien conjuntamente variables psicológicas, variables 
biológicas (actividad inmune por ejemplo) y progresión de la enfermedad, y naturalmente, toda posible inferencia extraída de la investigación con animales ha de estar llena de matizaciones.

Cuando se habla de mediadores se está descartando una relación causa-efecto entre factores psicológicos y aparición/desarrollo del cáncer. Volvemos el argumento expuesto en introducción de este artículo: la «etiología» psicosomática implica un aumento de la vulnerabilidad a la disfunción biológica producida por factores psicológicos. ¿Cuáles serían los eslabones intermedios de la cadena? ¿Qué mecanismos pueden controlar la influencia de los factores psicológicos sobre la vulnerabilidad a la enfermedad? Lo que vulgarmente se conoce bajo el nombre de cáncer, aun con un denominador común icélulas que se reproducen de forma incontrolada), agrupa a más de 100 enfermedades diferentes, y el conocimiento que se posee sobre los procesos que subyacen a ellas es todavía muy limitado. Averiguar la influencia que pueden ejercer variables que actúan a un nivel molar (psicológicas) sobre un nivel celular, molecular, necesitaría a su vez de un conocimiento más exacto de todos esos procesos subyacentes. Por poner un ejemplo posiblemente más relevante a esta argumentación, el papel del sistema inmunológico (el mecanismo mediador entre variables psicológicas y cáncer más invocado en la literatura) en la defensa del organismo frente al cáncer es objeto actualmente de polémica en el propio campo de la inmunología. Se comprende, pues, cómo un esfuerzo interdisciplinar como el que planteamos en nuestro trabajo es realmente arduo aunque necesario.

La investigación de la relación entre variables psicológicas y neoplasia se ha centrado fundamentalmente en dos sistemas mediadores: el sistema neuroendocrino y el sistema inmunológico (Levy, 1982, pref.; Borysenko, 1982; Fox, 1981; Lippman, 1982), basándose en los vínculos que cada uno de ellos parecen mantener con el sistema nervioso por un lado, y con los procesos implicados en la aparición y desarrollo del tumor, por otro.

\section{A) El sistema neuroendocrino}

Tal y como vimos al describir las consecuencias fisiológicas del estrés, es de la vinculación entre el sistema nervioso y el sistema endocrino de la que mayor información disponemos. No vamos a repetir esa descripción, sólo recordar que la experiencia psicológica estresante provoca alteraciones neuroquímicas en el hipotálamo que desencadenan la secreción de ACTH en la pituitaria, que al alcanzar el córtex adrenal estimulará la síntesis y liberación de corticoides. Por otra parte, ante la estimulación simpática, la médula adrenal liberará catecolaminas. Aparte de los corticoides y las catecolaminas, que históricamente han sido los asociados al estrés, ya se sabe que también aumenta la liberación de otras hormonas (prolactina, tirotropina, vasopresina, etc.) que pueden tener efectos sobre el desarrollo neoplásico.

Esta pauta fisiológica ante estímulos nuevos o aversivos, en sistemas animales, se ha visto que puede estar modulada por una serie de variables, como ya vimos (vid. también discusión en el apartado dedicado al cáncer experimental). La pauta es adaptativa en el sentido de que prepara al organismo para una respuesta inmediata. Pero la movilización de recursos que supone puede acarrearle también consecuencias negativas. En concreto, estas alteraciones sobre el medio endocrino pueden modificar la vulnerabilidad al desarrollo neoplásico bien directamente (caso de los tumores hormonodependientes) o bien indirectamente, alterando otros tejidos o sistemas implicados o responsables en alguna medida de la progresión del cáncer (el más obvio es el sistema inmunológico) (vid. revisión de Lippman, 1982). Por otra parte, muchos tumores secretan hormonas ectópicas que pueden afectan a su vez a neoplasias dependientes de hormonas y a tejido no neoplásico. Los carcinomas de mama, de endometrio, de próstata, junto con las leucemias y los linfomas son ejemplos clásicos y bien documentados de neoplasias dependientes de hormonas específicas. Esta influencia directa no descarta la posibilidad de una acción indirecta del me- 
dio endocrino sobre la vulnerabilidad del organismo al cáncer, en primer lugar a través del sistema inmunológico, pero también mediante otros mecanismos, como puede ser, por ejemplo, modificando la tasa de replicación del ADN.

\section{B) El sistema inmunológico}

Ya hemos realizado en otro lugar de este artículo un breve resumen de los componentes del sistema inmune con sus respectivas funciones. Datos que avalan que el sistema inmune puede ser objeto de una regulación parcial por parte del sistema endocrino son abundantes en la literatura (Ahlqvist, 1981). Así, por ejemplo, parece demostrado que los corticoides, en ciertas dosis, poseen un efecto inmunosupresor, en sistemas animales (e.g., Riley, 1981) y seres humanos (e.g., Haynes y Fauci, 1978). Además de disminuir el número total de linfocitos, también deterioran varias funciones inmunológicas específicas. Estas propiedades inmunodepresoras de los corticoides se utilizan clínicamente, por ejemplo, para impedir reacciones de rechazo en casos de trasplantes. También se ha demostrado que los linfocitos poseen en su superficie receptores de una serie de hormonas y neurotrasmisores que afectan a su actividad funcional, fundamentalmente a través de la producción de AMP cíclico, que posee efectos inmunosupresores (Wunderlich, 1982).

La idea mantenida durante años de que la influencia del sistema nervioso sobre el sistema inmune se producía únicamente a través de la vía Hipotálamo-PituitariaCorteza Adrenal, es decir, a través de mecanismos neuroendocrinos, ha sido puesta en entredicho por varios estudios (e.g., Bartroo et al., 1977) en los que no se ha podido demostrar una relación entre niveles fisiológicos de varias hormonas, especialmente corticoides y una disminución en la inmunidad celular. Como ya señalamos, se dispone de diversas líneas de evidencia que demuestran que puede existir una relación directa entre ambos sistemas, nervioso e inmune, tanto a nivel anatómico como funcional (Locke, 1982).

El papel del sistema inmunológico en la defensa del organismo frente al desarrollo de tumores es actualmente objeto de estudio y, como ya hemos señalado, de polémica en el propio campo de la inmunología (Wunderlich, 1982). Se supone que el sistema inmune actúa más eficazmente una vez que se ha producido la transformación neoplásica, supuesto que para poder actuar antes debería reconocer a los agentes transformantes como extraños e inactivarlos, y muy pocos datos existen por ahora que demuestren que esto suceda así. Por otra parte, la respuesta inmune puede ser no sólo inhibidora sino también en algunos casos facilitadora del desarrollo del tumor. Pero aunque no parece haber respuestas definitivas ni mucho menos, los datos más importantes (además de otros procedentes de experimentación con métodos in vitro en seres humanos e in vivo e in vitro en animales; Herberman, 1982), que apoyan un protagonismo de la competencia inmunológica en la defensa frente al cáncer en el ser humano, pueden ser los siguientes (e.g., Levy, 1982, pref.; Wunderlich, 1982):

- Una mayor incidencia de tumores en personas con alteraciones inmunológicas de origen genético.

- Las intervenciones médicas inmunodepresoras potencian las enfermedades neoplásicas.

- Tumores cuyo tejido muestra una infiltración de linfocitos, células plasmáticas y macrófagos suelen tener un mejor pronóstico.

Esta competencia inmunológica se traduce en varios mecanismos antitumor que son activados y regulados por numerosos factores, en muchos casos independientes entre sí, y que muchas veces no tienen su origen en el propio sistema inmune (e.g., sistema endocrino, o SNC directamente). Los mecanismos antitumor que se han identificado hasta el momento son de dos tipos: los que implican algún tipo de reacción de anticuerpo ante características an- 
tigénicas del tumor (dependiente por tanto de linfocitos B y T) y los que no lo implican, es decir, reaccionan ante el tumor espontáneamente (macrófagos y actividad NK) (Wunderlinch, 1982).

Una gran parte de la investigación relacionada con la inmunología del cáncer está realizada es animalen. De entre las muchas precauciones necesarias a la hora de hacer inferencias con respecto al ser humano, está la que se refiere al sistema de tumor utilizado (su histocompatibilidad con el organismo huésped, de la que dependerá el tipo de reacción inmune). La mayoría de los tumores animales investigados son trasplantados o inducidos por dosis muy fuertes de carcinógenos, y en la especie humana la mayor parte de los tumores son espontáneos o inducidos por dosis carcinogénicas pequeñas y continuas (véase, por ejemplo, la discusión de Fox, 1981). Otro problema de los estudios psicoinmunológicos, en general, es el de los niveles basales de las variables inmunológicas estudiadas, que habría que tener en cuenta dada su considerable variabilidad inter $e$ intraindividual (Rogers et al., 1979).

Si no hay respuestas claras y definitivas con respecto al papel del sistema inmune frente al cáncer, no sorprende que no se conozca con certeza su actuación como posible mediador entre variables psicológicas y la neoplasia, tanto en la fase de transformación o iniciación como en la de promoción de las células cancerosas. Aunque, como hemos señalado, la influencia parece mucho más probable en esta última etapa (Borysenko, 1982), si es que la actuación del sistema inmunológico es más eficaz durante los primeros momentos de ella que en la etapa de iniciación.

\section{CONCLUSIONES GENERALES}

Tras la lectura de estas líneas (vid., por ejemplo, las conclusiones de los apartados dedicados a investigaciones con animales y con seres humanos), algún lector podría sacar la conclusión de que no hay una lí- nea clara de trabajo en este campo. Desde luego no es esa nuestra impresión, aunque la conclusión fundamental que se puede extraer de la revisión de los trabajos en los que se ha intentado estudiar las relaciones entre variables psicosociales y cáncer sea precisamente la ausencia de datos definitivos. Si parece desprenderse de ellos que factores psicológicos juegan algún papel en el origen y desarrollo de la enfermedad, pero aun cuando ésta es la conclusión en un gran número de estudios, hay resultados contradictorios con respecto a la dirección de esa influencia. Para poder clarificar el campo necesitaríamos un número mayor de estudios longitudinales, bien diseñandos, de muestras amplias y con un control continuado de las variables biológicas sugeridas como mediadores de la posible influencia psicológica (fundamentalmente, neuroendocrinos e inmunológi$\cos )$. Conocemos las graves dificultades que esto puede entrañar, y suponemos que éstas explican que no se hayan realizado apenas estudios de estas características, no sólo en nuestro país, sino también fuera de él. En España es especialmente difícil debido a la escasa tradición que existe de trabajo interdisciplicar (en este caso, oncólogos, inmunólogos, bioquímicos, etc.).

En las primeras Jornadas de Psicología Oncológica (Barcelona, 1984) tuvimos la oportunidad de conocer las diferentes lineas de investigación que se están llevando a cabo en nuestro país. Se presentaron en ellas algunos estudios descriptivos en los que se analizaba el perfil psicológico de pacientes con distintos tipos de cáncer. En lo que respecta a las posibles aplicaciones clínicas, estos estudios pueden ayudar a establecer los objetivos de la intervención y las estrategias adecuadas de enfrentamiento a los problemas que pueden asociarse a esta enfermedad. Sin embargo, si el objetivo es la prevención de la aparición del cáncer, creemos que estamos todavia muy lejos de poder establecer indicadores psicosociales de riesgos, para lo cual seria necesario utilizar un enfoque metodológico diferente, tal y como hemos señalado anteriormente. 


\section{Notas}

${ }^{1}$ El problema del dualismo ha sido también un caballo de batalla entre los psicólogos. Bas (1982) piensa que los psicólogos no se han planteado a fondo el problema y que, es más, "lo han dejado en manos de los filósofos, debido a que esta discusión podría afectar a los propios sistemas de creencias (religiosos, ideológicos, etc.) muy apreciados y sostenidos por una larga historia de aprendizaje social" (pág. 63). Este comentario puede aplicarse a una parte importante de la clase médica que, voluntaria o involuntariamente, en su práctica diaria sostiene un punto de vista dualista.

2 Beck recomienda, por ejemplo, el abandono de la división clásica entre depresión reactiva y endógena, tan utilizada hoy en día en el diagnóstico psiquiátrico, considerando que es un enfoque limitado y engañoso (Beck, 1983).

${ }_{3}$ Para Lazarus, que ha sido el principal introductor de los elementos cognitivos en la investigación del estrés, el juicio o percepción de la significación de la situación estresante (valoración primaria) y la evaluación de las capacidades de enfrentamiento (valoración secundaria) y su puesta en funcionamiento, constituyen un determinante fundamental de la respuesta de estrés (e.g., Lazarus, 1966).

${ }^{4}$ NKC son las iniciales correspondientes a "Natural Killer Cells", cuya traducción del inglés podría ser la de "células asesinas naturales", o células que eliminan a otras (reconocidas como extrañas al organismo de forma "natural», es decir, sin necesidad de sensibilización previa.

5 No podemos entrar en más detalles. Para una mayor información ver Anisman y Sklar, 1982, y Riley et al., 1982 .

6 Es pertinente referir al lector a la distinción que Fox (1981) realiza entre "etiología psicosocial exógena" (conductas que exponen al organismo a diversos carcinógenos) y "etiología psicosocial endógena" (estados psicológicos que aumentan la vulnerabilidad a la acción de esos carcinógenos) (págs. 103-104).

\section{Resumen}

Se presenta en este artículo una introducción al campo de estudio de las relaciones entre factores psicosociales y neoplasia, enmarcándolo dentro de la medicina conductual y' desde un enfoque interdisciplinar. A continuación se discute el papel que pueden desempeñar las variables psicosociales (estrés) en la vulnerabilidad del ser bumano a la enfermedad en general a través de su acción sobre el sistema inmune. En el apartado III se realiza una revisión critica en la investigación en la que se ba intentado delimitar la influencia de factores psicosociales en la aparición y pronóstico del cáncer, en animales (cáncer experimental) $y$ en el ser humano. Se discute por último el papel de los mediadores biológicos propuestos como más importantes hasta el momento en la literatura del área (sistemas neuroendocrino $e$ inmune). De esta revisión se desprende que los resultados de la investigación, aunque sugerentes no son definitivos, ni tampoco están claros los mecanismos biológicos a tracés de los cuales se puede producir la influencia. Después de analizar algunas de las deficiencias metodológicas más importantes de los trabajos realizados, creemos que en enfoque más adecuado para poner a prueba la bipótesis de que los factores psicosociales afectan al desarrollo del cáncer deberia ser longitudinal, utilizando grandes muestras y estudiando ciariables psicosociales y biomédicas conjuntamente.

\section{Abstract}

An introduction to research about relationships between psychosocial factors and neoplasia, set within the point of view of the behavioral medicine and with an interdisciplinary perspective is presented. The role that psychosocial variables (stress) in buman susceptibility to disease in general may play through their acion on the immune system is discussed. The state of research that has attempted to delimit the influence of psychosocial factors on development and outcome of cancer in animals (experimental cancer) and bumans is reviewed critically in Section III. Finally the role of the most important biological mediators so far proposed (neuroendocrine and immune systems) is discussed. This review reveals that the empirical evidence of psychosocial influence on cancer, although suggestive it is not conclusive and the biological mechanisms which could mediate such influence are not clear eitber. We believe that the best test of the hypothesis that psychosocial factors affect cancerous growth require a prospective approach which utilizes large samples and the study of psychosocial and biomedical variables jointly in order to eliminate the most important methodological deficiences of research up to date carried out. 


\title{
Résumé
}

\begin{abstract}
On présente dans cèt article, une introduction au champs d'étude des relations entre facteurs psychosociaux et néoplasie, dans le cadre de la médecine behavioriste et d'un point de vue interdisciplinaire. Ensuite, on discute le rôle que peuvent jouer les variables psychosociales (stress) dans la vulnérabilité de l'être bumain à la maladie en général a travers leur action sur le système immunologique. Dans le partie $I I I$, on effectue une révision critique des recherches dans lesquelles on a tenté de délimiter l'influence des facteurs psychosociaux, sur l'apparition et le pronostic du cancer, chez les animaux (cancer expérimental) et chez l'être bumain. On discute, en fin, le rôle des médiateurs biologiques proposés comme les plus importants à ce jour dans le litterature du domaine (système neuroendocrinien et immunologique). Il se dégage, de cette révision, que les résultats de cettes recherches, bien que suggestives, ne sont pas défininives et que les mécanismes biologiques à travers lesquels l'influence peut exàercer ne sont pas clairs. Après avoir analysé certaines déficiences mé-

thodologiques, les plus importantes des travaux realisés, nous croyons que la perspective la plus adéquate pour tester l'bypotbèse que les facteurs psychosociaux affectent le développement du cancer devrait être longitudinale en utilisant de grands échantillons, et en étudiant ensemble des variables psychosociales et biomédicales.
\end{abstract}

\section{Referencias}

Asse, D. W.; WILkINS, M. M.; VAN DE CASTLE, R. L., et al.: "Personality and behavioral charasteristics of lung patients". J. Psychosom. Res, 18, 101-13, 1974.

ADER, R.: "Psychosomatic and psychoimmunologia research". Psychosom. Med., 42, 307-21, 1980.

ADER, R.: "Behavioral influences on immune responses". En S. M. Weiss, J. A. Herd y B. H. Fox (Dirs.): Perspectives on Behavioral Medicine. Nueva York: Academic Press, 1981 a.

ADER, R. (Dir.): Psychoneuroimmunology. Nueva York: Academic Press, $1981 \mathrm{~b}$.

ADER, R., y COHEN, N.: «Behaviorally conditioned immunosuppresion». Psychosom. Med., 37, 333-40; 1975.

ADER, R., y FRIEDMAN, J. B.: "Differential early experiences and susceptibility to transplanted tumor in the rat».J. Comp. Phisiol., S9, 361-4, 1965.

AHLQVIST, J.: «Hormonal influences on immunologic and related phenomena». En R. Ader (Dir.): Psychoneuroimmunology. Nueva York: Academic Press, 1981.

Alexander, F., y FlaGG, G. W.: "The psychosomatic approach». En B. B. Wolman (Dir.): Handbook of clinical psychology. Nueva York: McGraw-Hill, 1965.

Amkraut, A., y Solomon, G. F.: "Stress and murine sarcoma virus (moloney) induced tumors". Cancer Research, 32, 1428-33, 1972.

AMkraut, A., y SOLOMON, G. F.: "From the symbolic stimulus to the pathophysiologic response: immune mechanisms». Int. J. Psychiat. in Med., 5, 541-63, 1975.

ANISMaN, H., y SKLAR, L. S.: "Stress provoked neurochemical changes in relation to neoplasia". En S. Levy (Dir.): Biological Mediators of Bebavior and Disease: Neoplasia. Nueva York: Elsevier, 1982.

BACON, C. L., RENNEKER, R., y CuTleR, M.: «A psychosomatic survey of cancer of the breast". Psychosom. Med., 14, 453-60, 1952.

BAHNSON, C. B., y BAHNSON, M. B.: "Role of the ego defenses: denial and repression in the etiology of malignant neoplasm*. Ann. NY Acad. Sci., 123, 827-45; 1966.

BARReto, P., IBAÑEZ, E., y CAPAFONS, A.: Variables de vulnerabilidad al estrés y depresión en pacientes con cáncer de mama. Análisis global. Comunicación presentada en las Primeras Jornadas de Psicología Oncológica. Barcelona, 1984.

Bartrop, R. W.; Lazarus, L.; Luckhurst, E.; Kiloh, L. G., y PenNy, R.: «Depressed lymphocyte function after bereavement». Lancet, I, 834-6, 1977.

BAS, F.: La transferencia de la autocredibilidad: un ensayo experimental. Memoria de licenciatura no publicada. Univ. Autónoma de Madrid, 1982.

BECK, A. T.: "Cognitive therapy of depression: New perspectives". En P. J. Clayton y J. E. Barret (Dirs.): Treatment of Depression: Old Controversies and New Approaches. Nueva York: Raven Press, 1983.

BERNDT, H.; GUNTHER, H., y ROTHE, G.: «Persönlichkeits strucktur uach Eysenck bei Krauken mit Brustdrüsen und Bronchialkrebs und Diagnoseverzögerung durch den Patienten». Arch. f. Geschwälstf, so, 1980.

Bieliauskas, L. A., y Garron, D. C.: "Psychological depression and cancer". Gen. Hosp. Psychiat., 4, 187-95, 1982. 
BloOM, B. L; Asher, S. J., y WhITE, S. W.: «Marital disruption as stressor: A review and analysis». Psychol. Bull., 85, 867-94, 1978.

BlumberG, E. M.; WEST, P. M., y Ellis, F. W.: «A possible relationship between psychological factors and human cancer». Psychosom. Med., 16, 277-86; 1954.

BLOOM, E. M., WEST, P. M., y ELLIS, F. W.: «MMPI findings in human cancer». En G. S. Welsh y W. G. Dahlstrom (Dirs.): Basic reading on the MMPI in psychology and medicine. Minneapolis: Univ. of Minnesota Press, 1956.

BORYSENKO, J. Z.: «Higher cortical funtion and neoplasia: Psychoneuroimmunology". En S. M. Levy (Dir.): Biological Mediators of Behavior and Disease: Neoplasia. Nueva York: Elsevier, 1982.

BORYSENKO, M., y BORYSENKO, J.: «Stress, behavior, and immunity: Animal models and mediating mechanisms». Gen. Hosp. Psychiat., 4, 59-67; 1982.

Bower, G. H.: "Mood and memory". American Psychologist, 36, 129-48, 1981.

BURCHFIELD, S. R.: "The stress response: A new perspective». Psychosom. Med., 41, 661-72; 1979.

Cannon, W. G.: Bodily Changes in Pain, Hunger, Fear and Rage: An Account of Recent Researches into the Function of Emotional Excitement. (2.2 ed.). Nueva York: Appleton, 1929.

Carrobles, J. A. I.: El biofeedback y sus aplicaciones. Reunión Nacional sobre Intervención Psicológica. Murcia, 1982.

Coppen, A., y MetCalfe, M.: "Cáncer y extraversión». Brit. Med. J., 6, 18-19; 1963.

CuRTIS, G. C.: "Psychoendocrine stress response: Steroid and peptide hormones". En B. A. Stoll (Dir.): Mind and Cancer Prognosis. Chichester: John Wiley \& Sons, 1979.

Chesney, M. A., y Rosenman, R. H.: «Specificity in stress models: Examples drawn from Type A behavior". En C. L. Cooper (Dir.): Stress Research. Issues for the Eighties. Nueva York: John Wiley \& Sons, 1983.

DATTORE, P.; ShONTZ, F., y COYNE, L.: "Premorbid personality differentiation of cancer and non-cancer groups. J. Consult. Clin. Psychol., 48, 388-94, 1980.

DAY, N. E., y BOWN, C. C.: "Multistage models and primary prevention of cancer".J. Natl. Cancer Inst., $64,977-89 ; 1980$.

DeChanbRe, R. D., y Grosse, C.: "Individual versus group caging of mice with grafted tumors". Cancer Research, 33, 140-4; 1973.

DeROGATI, L. R., y ABELOFF, M. D.: "Psichological aspects of management of primary and metastatic breast cancer". En A. C. W. Montagne, G. L. Stonesifer y E. F. Lewinson (Dirs): Breast cancer: Progress in clinical and biological research (vol. 12). Nueva York: Liss, 1977.

Derogatis, L. R.; AbelofF, M. D., y Melisaratis, N.: «Psychological coping and survival time in metastatic breast cancer. J. Am. Med. Ass., 242, 1504-8; 1979.

DolL, R.: «Strategy for detection of cancer hazards to man. Nature, 265, 589-96; 1977.

Dorian, B. J., KEYSTONE, E., y GARFinkel, P. E. et al.: "Immune mechanisms in acute psychological stress." Psychosom. Med., 43, 84 (Abstract); 1981.

ENGEL, G. L.: "The need for a new medieval model: A challenge for biomedicine." Science, 196, 129-36; 1977.

ERnster, V. L.; SACKS, T., y PETRAkIS, N. C.: “Cancer incidence by marital status: U. S. Third National Cancer Survey. J. Natl. Cancer Inst., 63, 567-85; 1979.

Evans, E.: A psychological study of cancer. Nueva York: Dodd-Mead, 1926.

EYSENCK, H. J.: aPersonality and cancer: some comments on a paper by Berndt, H. et. al. Arch.f. Gerwülstf, $51,442-3 ; 1981$.

EYSENCK, H. J.: «Stress, disease, and personality: The Inoculation Effect`". En C. L. Cooper (Dir.): Stress Research. Issues for the Eighties. Nueva York: John Wiley \& Sons, 1983.

Fauman, M. A.: "The Central Nervous System and the Immune System". Biolog. Psychiat., 17, 1459-82; 1982.

Fernández Ballesteros, R.: «Los autoinformes". En R. Fernández Ballesteros (Dir.): Psicodiagnóstico (Tomo 1). Madrid: UNED, 1983.

FISHER, B., y FISHER, E. R.: «Experimental studies of factors influencing hepatic metastases: II. Efect of partial hepatectomy". Cancer, 12, 929-32; 1959.

FORNER, E.: Memoria, pensamiento y valores en pacientes cancerosas. Memoria de licenciatura no publicada. Facultad de Psicologia, Univ. Literaria de Valencia, 1984.

Fox, B. H.: "Premorbid psychological factors as related to cancer incidence. J. Behav. Med., 1, 45-133; 1978.

Fox, B. H.: "Psychosocial factors and the immune system in human cancer" En R. Ader (Dir.): Psychoneuroimmunology. Nueva York: Academic Press, 1981.

FRANKENHAUSER, M.: «Psychoneuroendocrines approaches to the study of stressful person-environment transactions». En H. Selye (Dir.): Selye's Guide to Stress Research. Nueva York: Van Nostrand Reinhold, 1980 (págs. 46-70).

FreEman, W.: "Biometrical studies in psychiatry: The chances of death". Am. J. Psychiat., 8, $425 ; 1928$.

GERSHBeN, L. L.; BenUCK, I., y SHURRAGER, P. S.: "Influence of stress on lesion growth and on survival of animals bearing parenteral and intracerebral leukemia L 1210 and Walker tumors". Oncology, 30, $429-35 ; 1974$.

GrEeNE, W. A.: «The psychosocial setting of the development of leukemia and lymphoma». Ann NY Acad. Sci., 12S, 794-801; 1966. 
GREER, S., y MORRIS, T.: «Psychological attributes of women who develop breast cancer: a controlled study". J. Psychosom. Res., 19, 147-153; 1975.

Greer, S.; MORRIS, T., y PeTtingale, K. W.: «Psychological response to breast cancer: Effect on outcome.» Lancet, 2, 785-7; 1979.

GREER, S., y SILBERFARB, P. M.: «Psychological concomitants of cancer: Current state of research. Psychol. Med., 12, 563.73; 1982.

Grissom, J. J., WeINER, B. J., y WeINER, E. A.: «Psychological correlates of cancer». J. Consult. Clin. Psychol., 43, 113; 1975.

Grossath-MATICEK, R.; KANAZiR, D. T.; SChMidt, P., y VetTeR, H.: "Psychosomatic factors in the process of cancerogenesis: Theoretical models and empirical results". Psychother. Psychosom., 38, (1-4): 284-302; 1982

HAGNELL, O.: *The premorbid personality of persons who develop cancer in a total population investigated in 1947 and 1957\%. Ann. NY Acad. Sci., 125, 846-55; 1966.

HawkINS, N. G.; DAviES, R., y Holmes, T. H.: «Evidence of psychosocial factors in the development of pulmonary tuberculosis». Amer. Rev. Tuberc. Pulmon. Dis., 75, 768-80; 1957.

HAYNES, B. F., y FAUCI, A. S.: "The differential effect on the kinetics of subpopulations of human peripheral blood thymus-derived lymphocytesn. J. Clin. Invest., 61, 703-7; 1978.

HENRY, J. P., y STEPHENS, P. M.: Stress, Health, and the Social Environment: A Sociobiologic Approach to Medicine. Nueva York: Springer-Verlag, 1977.

HENRY, J. P.; STEPHENS, P. M., y WATSON, F. M. C.: «Force breeding, social disorder and mammary tumor formation in CBA/USC mouse colonies. A pilot study. Psychosom. Med., 37, 277-83; 1975.

HEBERMAN, R.B.: «Possible effects of central nervous system on natural Killer (NK) cell activity". En S. M. Levy (Dir.): Biological Mediators of Behavior and Disease: Neoplasia. Nueva York: Elsevier, 1982.

Heberman, R. B., y Holden, H. T.: «Natural killer cells as antitumor effector cellsm. J. Natl. Cancer Ins., $62,441-55,1979$.

Hernández, E.; Tejero, A.; Salvador, L.; Colomer, R., y Lobo, A.: Análisis dimensional de la personalidad según Eysenck en pacientes afectas de neoplasia de mama. Comunicación presentada en las Primeras Jornadas de Psicología Oncológica. Barcelona, 1984.

Holmes, T. H., y RaHe, R. H.: "The social readjustment rating scale». J. Psychosom. Res., 11, 213-18, 1967.

HORNE, R. L., y PICARD, R. S.: «Phichosocial risk factors for lung cancer». Psychosom. Med., 41, 503-14, 1979.

JaCOBS, T. J., y Charles, E.: «Life events and the occurrence of cancer in children». Psychosom. Med., 42, $11-24,1980$.

JAMASBI, R. J., y NETTESHEIM, P.: «Non-immunological enhancement of tumor transplantabily in $\mathrm{x}$-irradiated host animals. Brit. J. Cancer, 36, 723-29, 1977.

JEMMOTT, J. B.; III, y LOCKE, S. E.: «Phychosocial factors, immunologic mediation, and human susceptibility to infections diseases: How much do we know?». Psychol. Bull., 95, 78-108, 1984.

JENKINS, D. C.: «Recent evidence supporting psychologic and social risk factors for coronary disease". New Eng. J. Med., 294, 987-94; 1033-8, 1976.

KASL, S. V.: «Pursuing the link between stressful life experiences and disease: A time for reappraisal». En C. L. Cooper (Dir.): Stress Research. Issues for the Eighties. Nueva York: John Wiley \& Sons, 1983.

KAVETSKY, R. E.; TURKEVICH, N. M., y BALITSKY, K. P.: «On the psychophysiological mechanisms of the organism's resistance to tumor growthm. Ann. NY Acad. Sci., 125, 933-45, 1966.

Kiekolt-Glaser, J. K.; Garner, W.; Speicher, C.; Penn, G. M.; Holliday, J., y Glaser, R.: «Psychosocial modifiers of immunocompetence in medical studentes". Psychosom. Med., 46, 7-14, 1984.

KISSEN, D.: «Personality characteristics in males conducive to lung cancer». Brit. J. Med. Psychol., 36, 27-36, 1963.

KISSEN, D. M.: «Relationship between lung cancer cigarette smoking, inhalation and personality». Brit. J. Med. Psychol., 37, 203-16, 1964.

KISSEN, D. M.: «The significance of personality in lung cancer in men». Ann. NY Acad. Sci., 125, 820-6, 1966.

KISSEN, D. M.: «Phichosocial factors, personality and lung cancer in men aged 55-64». Brit. J. Med. Psychol., $40,29-43,1967$.

KISSEN, D. M.: «Some methodological problems in clinical psychosomatic research with special reference to chest disease». Psychosom. Med., 30, 324-35, 1968.

Kissen, D. M., y EYsenek, H. J.: «Personality in male lung cancer patients». J. Psychosom. Res., 6, 123-37, 1962.

KoENIC, T.; LeVIN, S. M., y BRENNAN, M. J.: «The emotional status of cancer patients as measured by psychological test». J. Chron. Dis., 20, 923-30, 1967.

KRAUS, A. S., y LILIENFELD, A. M.: *Some epidemiologic aspects of the high mortality rate in the young widowed group». J. Chron. Dis., 10, 207-17, 1959.

LA Barba, R. C.: «Experiential and environmental factors in cancer: review of research with animals». Psichosom. Med., 32, 259-76, 1970.

LA BARBA, R. C., y WHITE, J. L.: «Maternal deprivation and the response to Ehrlich carcinoma in BALB/C micew. Psychosom. Med., 33, 458-60, 1971.

Lazarus, R. S.: Psychological Stress and the Coping Process. Nueva York: McGraw-Hill, 1966. 
Leiber, L.; Plumb, M. M.; Gerstenzang, M. L., y Holland, J.: "The communication of affection between cancer patients and their spouses". Psychosom. Med., 38, 379-89, 1976.

LESHAN, L.: «Psychological states as factors in the development of malignant disease: a critical review $\% . J$. Natl. Cancer Inst., 22, 1-18, 1959.

LESHAN, L.: «An emotional life-history pattern associated with neoplasic disease". Ann. NY Acad. Sci., 125, 780-93, 1966.

LESHAN, L., y WOTHINGTON, R. E.: «Personality as factor in the pathogenesis of cancer: review of the literaturem. Brit. J. Med. Psychol., 29, 49-56, 1956.

LeVENDEL, L.; MEZEI, A.; ERDELY, E., y LITVAI, G.: "Study of the personality characteristics of lung-cancer patientsm. Zeitschrift F. Psychosom. Med. und Psychoanalse, 21, 270-83, 1975.

LEVY, S. M. (Dir.): Biological Mediators of Behavior and Disease: Neoplasia. Nueva York: Elsevier, 1982.

LIPPMAN, M.: «Interactions of psychic and endocrine factors with progression of neoplastic diseases». En S. $\mathrm{M}$.

Levy (Dir.): Biological Mediators of Behavior and Disease: Neoplasia. Nueva York: Elsevier, 1982.

LOCKE, S. E.: «Stress, adaptation, and immunity: Studies in humans». Gen. Hosp. Psychiat., 4, 49-58, 1982.

LOCKE, S. E.; HURST, M. W.; HEISEL, J. S., et al.: The influence of stress on the immune response. Reunión anual de la American Psychosomatic Society, Washington, DC, 1 abril 1978.

LOCKE, S. E., y KRAUS, L.: "Modulation of natural killer cell activity by life stress and coping ability". En S. M. Levy (Dir.): Biological Mediators of Bebavior and Disease: Neoplasia. Nueva York: Elsevier, 1982.

LOMBARD, H. L., y POTTER, E. A.: «Epidemiological aspects of cancer of the cervix: Hereditary and environmental factors». Cancer, 3, 960-8, 1950.

MASON, J. W.: "A reevaluation of the concept of non specificity in the stress theory». J. Psychiat. Res., 8, 323-33, 1971 .

MASON, J. W.: «Emotions as reflected in patterns of endocrine integration». En L. Levi (Dir.): Emotions: Their Parameters and Measurement. Nueva York: Raven Press, 1975 (págs. 143-81).

Monjan, A. A.: «Stress and immunologic competence: Studies in animals». En R. Ader (Dir.): Psychoneuroimmunology. Nueva York: Academic Press, 1981.

MONJAN, A. A., y COLlECTOR, M. J.: «Stress-induced modulation of the immune responsen. Science, 196, 307-8, 1977.

Morris, T.; Greer, S.; Pettingale, K. W., y Watson, M.: "Patterns of expression of anger and their psychological correlates in women with breast cancer". J. Psychosom. Res., 25, 111-7, 1981.

MORRIS, T.; GREER, S., y WhITE, P.: "Psychological and social adjustment to mastectomiy. A two-year follow-up study». Cancer, 40, 2381-7, 1977.

MORRISON, F. R., y PAFFenbarger, R. A., Jr.: «Epidemiological aspects of biobehavior in the etiology of cancer: A critical review». En S. M. Weiss, J. A. Herd y B. H. Fox (Dirs.): Perspectives on Behavioral Medicine. Nueva York: Academic Press, 1981.

MURPHY, D. P.: Heredity in uterine cancer. Cambridge, Mass.: Harvard Univ. Press, 1952.

Mustin, H. L.; GYARFAS, K., y PIEPER, W. J.: "Separation experience and cancer of the breast». Ann. NY Acad. Sci., 125, 802-6, 1966 .

NewBerry, B. H.: «Effects o Presumably Stressful Stimulation (PSS) on the development af animal tumors: Some inssues". En S. M. Weiss, J. A. Herd y B. H. Fox (Dirs.): Perspectives on Behavioral Medicine. Nueva York: Academic Press, 1981.

NEWBERRY, B. H.; GILDOW, J.; WOGON, J., y REESE, R. L.: «Inhibition of Huggings tumors by forced restraint”. Psychosom. Med., 38, 155-62, 1976.

NeWBERRY, B. H., y SENGBUSH, L.: «Inhibitory effects of stress on experimental mammary tumors". Cancer Detec. Prevent., 2, 225-33, 1979.

NEWTON, G.; BLY, G. G., y MCCRARY, C.: «Effects of early experience on the response to trasplanted tumor». J. Nerv. Ment. Dis., 134, 522-7, 1962.

NiebGURS, H. E. et al.: “The role of stress in human and experimental oncogenesis». Cancer Detec. Prevent., 2, 307-36, 1979.

Palmblad, J.: "Stress and immunologic competence: studies in man». En R. Ader (Dir.): Psychoneuroimmunology. Nueva York: Academic Press, 1981.

Palmblad, J.; Petrini, B.; Wasserman, J., et al:: «Limphocyte and granulocite reactions during sleep deprivation". Psychosom. Med., 41, 273-8, 1979.

PARKER, W.: Cancer: A study of ninety-seven cases of cancer of the female brast. Nueva York: 1885.

PAYKEL, E. S.: «Recent life events in the development of the depressive disorders". En R. A. Depue (Dir.): The psychobiology of the depressive disorders. Nueva York: Academic Press, 1979.

PEES, H. W.: «Influence of sugery and dexamethasone on cell-mediated immune responses in patients with meningiomas". Brit. J. Cancer, 35, 537-45, 1977.

PETERS, L. J., y KeLLY, H.: «The influence of stress and stress hormones on the transplantability of a nonimmunogenic syngenic murine tumor». Cancer, 39, 1482-8, 1977.

Peters, L. J., y MASON, K. A.: aInfluence of stress on experimental cancer». En B. A. Stoll (Dir.): Mind and Cancer Prognosis. Chichester: John Wiley \& Sons, 1979.

Pettingale, K. W.; Greer, S., y TeE, D. E. H.: «Serum IgA and emotional expression in breast cancer patients". J. Psychosom. Res., 21, 295-9, 1977.

Estudios de Psicología $.^{\circ} 25-1986$ 
Plaut, S. M., y Friedman, S. B.: «Psychosocial factors in infections disease». En R. Ader (Dir.): Psychoneuroimmunology. Nueva York: Academic Press, 1981.

PlUMB, M. M., y HOLLAND, J.: «Comparative studies of psyhological function in patients with advanced cancer-I. Self-reported depressive symptoms». Psychosom. Med., 39, 264-76, 1977.

POND, D. A., y MARATOS, J.: «Psychosocial interrelations of benign prostatic hypertrophy". J. Psychosom. Res., 21, 201, 1977.

PraDhan, S. N., y RAY, P.: "Effects of stress on growth of trasplanted and 7,12 - Dimethylbenz [a] anthracene-induced tumors and their modification by psuchotropic drugs». J. Natl. Cancer Inst, 53, 1241-5, 1974.

RabkiN, J. G., y Struening, E. L.: "Life events, stress and illness». Science, 194, 1013-20, 1976.

RAY, P., y PRADHAN, S. N.: "Growth of transplanted and induced tumors in rats under a schedule of pu.nished behavior". J. Natl. Cancer Inst., 52, 575-7, 1974.

ReZnikOfF, M., y MARTin, D. E.: "The influence of stress on mammary cancer». J. Psychosom. Res., 2, $56-60,1957$.

RILEY, V.: «Mouse mammary tumors: Alteration of incidence as apparent function of stress». Science, 189, $465-7,1975$.

RiLEY, V.: «Psychoneuroendocrine influences on imnuno-competence and neoplasia». Science, 212, 1100-9, 1981.

Riley, V.; Fitzmaurice, M. A., y SPACKMAN, D. H.: «Psychonauroimmunologic factors in neoplasia: Studies in animals». En R. Ader (Dir.): Psichoneuroimmunology. Nueva York: Academic Press, 1981.

RiLEY, V.; FITZMAURICE, M. A., y SPACKMAN, D. H.: «Immunocompetence and neoplasia: Role of anxiety stress». En S. M. Levy (Dir.): Biological Mediators of Behavior and Disease: Neoplasia. Nueva York: Elsevier, 1982.

Rodríguez, J.; ANDreu, M. A.; Antón, M.; Lopez, S., y Palomar, A.: Análisis deferencial de rasgos de personalidad entre pacientes oncológicos hospitalizados y no hospitalizados. I Congreso del Colegio Oficial de Psicólogos, Area 3: Psicología y Salud. Madrid: Colegio Oficial de Psicólogos, 1984.

Rogentine, G. N., Jr.; van Kammen, D. P.; Fox, B. H.; DocherTy, J. P.; Rosenblatt, J. E.; Boyd, G. C., y BUNNEY, W. E., Jr.: «Psychological factors in the prognosis of malignant melanoma: A prospective study». Psychosom. Med., 41, 647-55; 1979.

Rogers, M. P.; DubeY, D., y ReICH, P.: *The influence of the psyche and the brain on immunity and disease susceptibility. Psychosom. Med., 41, 147-64; 1979.

SABA, T. M., y ANTIKATZIDES, T. G.: «Decrease resistance to intravenous tumor cell challenge during reticuloendothelial depression following surgery". Brit. J. Cancer, 34, 381-9; 1976.

SChleifer, S. J.; Keller, S. E.; Camerino, M.; ThORNTON, J. C., y STEIN, M.: «Suppression of lymphocyte stimulation following bereavementm. J. Amer. Med. Ass., 250, 374-7, 1983.

SChmale, A. H., Jr., e IKER, H. P.: "The effect of hopelessnes in the development of cancer: I. The prediction of uterine cancer in women with atypical cytology». Psychosom. Med., 26, 634-5, 1964.

SCHMALE, A., e IkER, H.: "The psychosocial setting of uterine cervical cancer". Ann. NY Acad. Sci., 125, $807-13,1966$.

SCHONFIELD, J.: «Psychological and life-experience differences between Israeli women with bening and cancerous breast lesiones». J. Psychosom Res., 19, 229, 1975.

SCHWARTZ, G., y WEISS, S.: “What is behavioral medicine?" Psychosom. Med., 39, 377-81, 1977.

SELYE, H.: “A syndrome produced by diverse nocivous agents». Nature, 138, 32, 1936.

SELYE, H.: «The stress concept: past, present and future». En C. L. Cooper (Dir.): Stress Research. Issues for the Eighties. Nueva York: John Wiley \& Sons, 1983.

ShAPIRO, A. K., y MORRIS, L. A.: «The placebo effect in medical and psychological therapies". En S. L. Garfield y A. E. Bergin (Dirs.): Handbook of Psychotherapy and Behavior Change: An Empyrical Analysis. (2.2 ed.). Nueva York: John Wiley \& Sons, 1978.

Shekelle, R. B.; Raynor, W. J.; Ostfeld, A. M.; Garron, D. C.; Bieliauskas, L. A.; Shuguey, C. L.; Maliza, C., y OGLesby, P.: "Psychosocial depression and 17-year risk of death from cancer". Psychosom. Med., 43, 117-25, 1981.

SKLAR, L. S., y ANISMAN, H.: «Stress and coping factors influence tumor growth». Science, 205, 513-5, 1979.

SkLAR, L. S., y ANISMAN, H.: «Stress and cancer». Psychol. Bull., 89, 369-406, 1981.

SNOw, H.: Cancer and the cancer process. Londres: Churchill, 1893.

Solomon, G. F.; Amkraut, A. A., y RuBin, T. T.: "Stress and psychoimmunological response». En B. Stoll (Dir.): Mind and Cancer Prognosis. Chichester: John Wiley \& Sons, 1979.

STAVRAKY, K. M.; BUCK, C. N.; LOTT, J. S., et al.: "Psychological factors in the outcome of human cancer". J. Psychosom. Res., 12, 251-9, 1968.

STEIN, M.; KelLER, S., y SCHLEIFER, S.: *Role of the hypothalamus in mediating stress effects on the immune system». En B. A. Stoll (Dir.) Mind and Cancer Prognosis. Chichester: John Wiley \& Sons, 1979.

StEIN, M.; SCHLEIFER, S. J., y KelLER, S. E.: «Hipothalamic influences on immune responses». En R. Ader (Dir.): Psychoneuroimmunology. Nueva York: Academic Press, 1981.

Stoll, B. A. (Dir.): Mind and Cancer Prognosis. Chichester: John Wiley \& Sons, 1979.

THOMAS, C. B.; DUSZINSKI, K. R., y SAHAFFER, J. W.: «Family attitudes reported in youth as potential predictors of cancer». Psychosom. Med., 41, 287-302, 1979. 
TURKEVICH, N. M.: «The development of the neoplastic process during functional changes of the higher part of the nervous systemm. En R. E. Kavetsky (Dir.): The neoplastic process and the nervous system. The State Medical Publishing House, 1958. Publicado por NSF, Washington, DC, 1960.

VAN DEN BRENK, H. A. S.; STONE, M. G.; KellY, H., et al.: *Lowering of innate resistance of the lungs to the growth of blood-borne cancer cells in states of topical and systemic stress". Brit. J. Cancer, 33, 60-78, 1976.

Visintainer, M. A.; Seligman , M. E. P., y Volpicelli , J.: «Helplessness, chronic stress and cumor development. Psychosom. Med., 45, 75-6, 1983 (abstract).

WALLACE, E. W.; WaLlaCE, H. H., y MiLls, C. A.: «Effect of climatic environment upon the genesis of subcutaneous tumors induced by methylcholanthrene and upon the growth of a transplantable sarcoma in C3H micen. J. Natl. Cancer Inst., 3, 99-110, 1942.

WATSON y SCHulD, D.: «Psychosomatic factors in the etiology of neoplasms". J. Consult. Clin. Psychol., 4S, 455-61, 1977.

WAYNER, L.; COX., T., y MACKAY, C.: «Stress, immunity and cancer». En D. J. Osbourne, M. M. Gruenberg y J. R. Eiser (Dirs.): Research in Psychology and Medicine (vol. 1). Nueva York: Academic Press, 1979.

WEISMAN, A. D.: «Early diagnosis of vulnerability in cancer patients". Am. J. Med. Sci., 27, 187, 1976.

Williams, J. M.; Peterson, R. G.; SheA, P. A., et al.: «Sympathetic innervation of murine thymus and spleen: Evidence for a functional link between the nervous and immune systems". Brain Res. Bull, 6, 83-94, 1981.

WITZEL, L.: "Anamnese und zeiterkraunkungen bei patienten mit bosartigen neubildungen». Med. Klin, 65, $876-9,1970$.

WORDEN, J. W., y WeISMAN, A. D.: «Psychosocial components of lagtime in cancer diagnosis". J. Psychosom. Res., 19, 69-79, 1975.

WUNDERLICH, J.: «Behavioral regulation of immunity: Implications for human cancer». En S. M. Levy (Dir.): Biological Mediators of Behavior and Disease: Neoplasia. Nueva York: Elsevier, 1982. 